REVISTA DE DERECHO UNED, NÚM. 25, 2019

\title{
LA VENTANILLA ÚNICA DE CERTIFICACIÓN AMBIENTAL
}

\author{
THE ONLY TICKET WINDOW OF ENVIRONMENTAL \\ CERTIFICATION
}

\author{
Alcides Antúnez SÁNCHEZ ${ }^{1}$
}

\begin{abstract}
Resumen: Desde principios del siglo XXI la modernización del sector público impulsado por las Tic ha desencadenado una serie de aspectos positivos y negativos para los ciudadanos; entre las reformas más innovadoras que ha sufrido el ambiente gubernamental ante el fomento de los procesos electrónicos a través del gobierno electrónico. El uso de las Tic busca reformar algunos procesos de la gestión pública y vincular activamente a los ciudadanos con la Administración para que se convierta en una herramienta que disminuya la carga burocrática en los trámites, promover la participación ciudadana, fortalecer la confianza en el Estado, viabilizar e incrementar la transparencia y la rendición de cuentas. Su implementación ha traído la modificación de modelos y políticas de gobierno por los Estados. Las actividades que los ciudadanos realizan con la Administración Pública se efectúan de forma electrónica desde finales del siglo XX, suceso que ha avanzado con la smart city.
\end{abstract}

Palabras llaves: gobierno electrónico, transparencia, eficacia, celeridad, ciudadanía.

Abstract: From the beginning of the century XXI the modernization of the public sector encouraged by the Tic has triggered a series of positive aspects and negatives for the citizens; Enter the most innovative reforms that you have suffered the governmental environ-

${ }^{1}$ Magister en Asesoría Jurídica. Profesor Auxiliar. Derecho Ambiental e Internacional. Facultad de Ciencias Económicas y Sociales. Universidad de Granma. República de Cuba. Email: aantunez@udg.co.cu, antunez63@nauta.cu

(C) UNED. Revista de Derecho UNED, núm. 25, 2019 
ment in front of the fomentation of the electronic processes through the electronic Government. The use of the Tic attempts to reform some processes of the public step and to link the citizens with Administration in order that that you decrease the bureaucratic load in the steps, to promote convert in a tool the civic participation itself actively, to strengthen the confidence in the State, viabilizar and to increment the transparency and accountability. The modification of models and governmental policies for the States has brought his implementation. XX, event make the activities that citizens accomplish with the Public Administration themselves of electronic form since late the century that city has advanced with smart.

Key words: Electronic Government, transparency, efficacy, celerity, citizenship

Recepción original: 07/03/2019

Aceptación original: 5/11/2019

SUMARIO: GLOSA INTRODUCTORIA. 1. 1. L A VE N T A N I LLA ÚNICA EN EL E-GOVERMENT. CONCEPTO, ORÍGENES, FUNCIÓN, EVOLUCIÓN Y REGULACIÓN NORMATIVA. 2. LA VENTANILLA ÚNICA DE CERTIFICACIÓN AMBIENTAL EN EL GOBIERNO DIGITAL EN CUBA. 3. CONCLUSIONES. 4. BIBLIOGRAFIA

\section{GLOSA INTRODUCTORIA}

En la actualidad se vive en una época de auge de las tecnologías digitales caracterizadas por constantes cambios e innovaciones científicas y tecnológicas al evolucionar de manera vertiginosa, siendo necesario apropiarse y actualizarse de las mismas para poder interactuar con ellas. En el mundo digital en que se vive hoy, la incursión del gobierno electrónico ha traído la modificación de los modelos clásicos y de las políticas de gobierno por los Estados, toda vez que muchas de las actividades que los ciudadanos realizan con la Administración Pública se efectúan de forma digital desde finales del siglo XX, suceso que ha avanzado en el siglo XXI con las ciudades inteligentes constituyendo lo que se ha denominado como una relación jurídica telemática. ${ }^{2}$

${ }^{2}$ Bernadí Gil, X. (2005) Derecho Público y Administración electrónica: una visión panorámica, Nuevas políticas públicas. Anuario multidisciplinar para la modernización de las Administraciones públicas, No 1, España; AA. VV. (2004) Administración electrónica y procedimiento administrativo, Ministerio de Economía, Madrid. 
La implementación de la estrategia E-government es uno de los elementos fundamentales en la modernización del sector público en el siglo XXI, no solamente porque permite el abastecimiento de información, sino que optimiza los procesos comerciales y facilita la comunicación entre los diferentes niveles del gobierno. Facilita el desarrollo de actividades de la Administración Pública relacionadas con los ciudadanos y las diferentes empresas al potenciar los servicios públicos. Con esta estrategia, los gobiernos han encontrado nuevas maniobras que propician la participación más activa de sus ciudadanos y ayudan a cumplir los mandatos constitucionales al apoyar la democracia con mayor transparencia; una de las estrategias más innovadoras es el uso de internet en la realización de diferentes procesos de comunicación para impulsar el gobierno digital. ${ }^{3}$ Estos procesos se ejecutan a través de la Ventanilla Única, ello permitirá analizar su concepto, evolución y reconocimiento jurídico en los Estados que la han implementado en sus ordenamientos jurídi$\cos ^{4}$

En el artículo se propone como objetivo caracterizar la Ventanilla Única de Certificación Ambiental dentro de los procesos vinculados al Derecho Ambiental dentro del ordenamiento jurídico por el Ministerio de Ciencias, Tecnología y Medio Ambiente para la gestión ambiental como parte de las políticas públicas en el fomento del gobierno digital en Cuba en la actualización de su modelo económico social. Para ello se han utilizado como materiales y métodos: el histórico lógico, el de inducción deducción, el de análisis síntesis, y el de comparación jurídica. El artículo está vinculado al Proyecto ECOIURE de la Unión Nacional de Juristas de Cuba en relación con la actualización de la Ley marco ambiental y con la Editorial Jurimestre en Brasil para su socialización.

${ }^{3}$ Castoldi, P. (2002) El gobierno electrónico como un nuevo paradigma de Administración. Revista Prudentia Juris, N 55. Buenos Aires; AA.VV. (2014) Gobierno electrónico: inclusión digital y poder popular, Revista Venezolana de Gerencia, Venezuela.

${ }^{4}$ Véase, Cerrillo Martínez, A. (2012) La contribución de las Tic a la mejora de la transparencia administrativa. Revista Arbor Ciencia, Pensamiento y Cultura, Vol. 188, España; Blasco Díaz, J. (2008) Los derechos de los ciudadanos en su relación electrónica con la Administración. Derechos fundamentales y otros estudios, Editorial Justicia de Aragón, Zaragoza; Cierco Seira, C. (2009) Algunas reflexiones sobre la simplificación de los procedimientos administrativos a la luz de los avances de la Administración electrónica, Revista General de Derecho Administrativo, No. 19, España.

(C) UNED. Revista de Derecho UNED, núm. 25, 2019 


\section{LA VENTANILLA ÚNICA EN EL E-GOVERMENT. CONCEPTO, ORÍGENES, FUNCIÓN, EVOLUCIÓN Y REGULACIÓN NORMATIVA}

\subsection{El E-goverment y la Ventanilla Única}

Las Tic han tenido un desarrollo vertiginoso desde el pasado siglo XX. De hecho, la innovación de las tecnologías ha crecido y evoluciona exponencialmente en el siglo XXI. Hoy las tecnologías que se implementan no solo tienen más capacidad de almacenamiento, mayor radio de alcance, mayor velocidad de transmisión, mayor aplicación o mayor grado de interactividad, sino también son en general más sofisticadas y han aumentado para una variedad de propósitos antes no concebidos. La tecnología evoluciona y cambia tan rápidamente que siempre hay nuevas tecnologías, actualizaciones y aplicaciones con las que el ciudadano y los servidores públicos interactúan. ${ }^{5}$

Una sociedad tecnológicamente avanzada se le ha dado en llamar, tanto por especialistas como por instituciones internacionales "Sociedad de la Información o Sociedad del Conocimiento". Castell, desde sus estudios la identifica como la Sociedad en Red en coincidencia con Pérez Luño, quien reconoce además la existencia del ciberespacio como un área para la comunicación, del comercio y la participación ciudadana en donde también se evocan nexos con la Ética y el Derecho. ${ }^{6}$

El desarrollo y crecimiento de las Tic ha impactado prácticamente todas las áreas de la actividad humana. Incide su utilización en todos los órdenes de la vida de las personas y como sociedad en los ámbitos económico, político, social, cultural, educativo, etc., reconfigurando la forma de percibir el mundo, los comportamientos y la forma de interrelación con las personas. La ciudadanía digital está comprendida en el modelo de la Sociedad del Conocimiento y la Información. ${ }^{7}$

${ }^{5}$ Dyson Freeman, J. (2000) El Sol, el genoma e internet. Las tres cosas que revolucionarán el siglo XXI: la energía solar, la ingeniería genética y la comunicación mundial, Editorial Debate, Madrid.

${ }^{6}$ Consúltese, Castells, M. (2005) La era de la información. La sociedad red, Editorial Alianza, Madrid; Pérez Luño, A. (2014) Teledemocracia, ciberciudadania y derechos humanos, Revista Brasilera de Políticas Públicas, №.2, Brasil.

7 Confróntese, Pérez Luño, A. (2004) ¿Ciberciudadani@o Ciudadani@.Com?, Editorial Gedisa, Barcelona; Robles Morales, J. (2009) Ciudadanía digital: una introducción a un nuevo concepto de ciudadano. Editorial UOC, Barcelona; Prenski, M. (2010) Nativos e Inmigrantes Digitales, Editorial SEK, España; Martínez-Villalva, J. 
Se aprecia el impulso que ha recibido el principio de simplificación en los últimos años desde el siglo XX con los actos de la Administración Pública, este tiene tras de sí una estrategia que ha acertado a aislar con una inédita determinación el instrumento de simplificación con la introducción de medios electrónicos en la gestión administrativa a través de las herramientas de las Tic. Se analiza la Ventanilla Única (VU) en la batalla contra la complejidad de la tramitación administrativa que concurre entre la Administración Pública y sus administrados. Este elemento constituye a criterio de los autores consultados el reto de la modernización administrativa con el uso de las Tic contra la burocracia de la Administración Pública en el siglo XXI. Su origen como mecanismo de la Administración Pública se aprecia que se desarrolla en el ámbito del comercio exterior entre los países. La VU ha cobrado actualidad en facilitar la actividad del comercio desde los finales del siglo XX. ${ }^{8}$

La comunidad comercial con la adopción de la VU le ha permitido simplificar la interacción con los organismos de control en frontera al rediseñarse todo el aparato de gobierno que interviene en los movimientos transfronterizos de mercancías y pasajeros con el fin de satisfacer las necesidades específicas de las empresas y de los ciudadanos en esta actividad mercantil en los servicios aduaneros. Las demoras, trabas o sobrecostos en el proceso de comercialización de mercancías a nivel internacional pueden conllevar a rezagos en el mercado o incluso la pérdida total del mismo. ${ }^{9}$

(2014) La cuarta ola de derechos humanos: los derechos digitales, Revista Latinoamericana de Derechos Humanos, México; Meneses Rocha, M. (2015) Ciberutopías. Democracia, redes sociales y movimientos-red. Editorial Porrúa, México.

8 Véase, Suñé Llinás, E. (2004) La Ventanilla Única Electrónica. Actas del X ${ }^{\circ}$ Congreso Iberoamericano de Derecho e Informática. Centro de Estudios en Derecho Informático, Chile; Salazar Solís, L. (2006) Ventanilla única de gobierno electrónico. Colección documentos de trabajo sobre e-Gobierno. Red de Líderes de Gobierno Electrónico de América Latina y El Caribe; Gamero Casado, E. (2009) Ventanilla única y administración electrónica en la transposición de la directiva de servicios, Universidad Pablo de Olavide de Sevilla, España; Castillo Y.A. (2016) Ventanilla única de trámites-Una aproximación conceptual. Monografías-Administración y finanzas. Disponible en: https://www.monografias.com/docs113/ventanilla-unicatramites-aproximacion-conceptual/ventanilla-unica-tramites-aproximacion-conceptual2.shtml.

${ }_{9}$ Consúltese, Arena, G. (2004) E-Government y Nuevos Modelos de Administración. Revista de Administración Pública Nº 163, España; Álamo González, N. (2007) La utilización de las nuevas tecnologías entre las Administraciones públicas y los ciudadanos, REDA, No 133, España; Canals Ametller, D. (2012) Simplificación administrativa y directiva de servicios: objetivos, medios e incidencias, el procedimiento administrativo: descarga burocrática, INAP, España. 
Los países que trabajen por mejorar la denominada "facilitación del comercio" con la implementación de la VU ponderan su uso en un gobierno abierto. He aquí a criterio de los articulistas su nexo con el Derecho Mercantil desde la integración de contenidos en la materialización de contratos, los cobros y pagos, la certificación ambiental, con la calidad ambiental, y la protección a los consumidores, entre otras. Como concepto fue introducido por primera vez en el programa de trabajo de la Organización Mundial del Comercio (OMC) y en la Declaración Ministerial de Singapur de 1996. Es un concepto central en la gran mayoría de los acuerdos comerciales que buscan como finalidad que los exportadores e importadores se beneficien de procedimientos más ágiles, transparentes y simplificados, que no sustituyan en ninguna medida a los aranceles y tarifas que se eliminan, se implementa en la contratación electrónica y los pagos, como en el marketing comercial. La División de Economía y Administración Pública de las Naciones Unidas (2002), señala que "el gobierno electrónico es un compromiso permanente del gobierno para mejorar la relación entre los ciudadanos y la administración pública, mediante el intercambio eficaz y eficiente de servicios, información y conocimiento". ${ }^{10}$

Por medio de la VU de Comercio Exterior las entidades comparten información y los usuarios realizan el trámite electrónico para obtener permisos, autorizaciones, y certificaciones exigidos por las entidades del Estado para las operaciones de comercio; como el acceso a consultar información sobre los procedimientos previos a la importación y exportación. Concepto que se ha construido sobre la Recomendación No. 33 de la ONU de 2005. ${ }^{11}$ En el 2005, el Centro de las Naciones Unidas para la Facilitación del Comercio y las Transacciones Electrónicas emitió la Recomendación y Directrices para el establecimiento de las Ventanillas Únicas de Comercio Exterior. Se partió de reconocer que en el comercio internacional existe una gran cantidad de requisitos y costos asociados, donde para cumplirlos pueden constituir un obstáculo para el desarrollo del comercio internacional. ${ }^{12}$ Una forma de abordar este problema en el comercio era el establecimiento de una VU que permitiera que la información y/o los documentos de carácter comercial se presenten solo una vez y en un único lugar en el E-goverment. Un servicio de este tipo busca mejorar

${ }^{10}$ ONU (2012) Estudio sobre Gobierno Electrónico. Departamento de Economía y Asuntos Sociales. New York.

${ }^{11}$ OMA (2012) Cómo construir un entorno de ventanilla única. Vol. 1. Guía Ejecutiva. OMC.

12 CEFACT/ONU (2005) Recomendaciones y Directrices para el Establecimiento de una ventanilla única. United Nations Publications; Ginebra. 
el principio de la eficacia y la rentabilidad de los controles oficiales. Permite reducir los costos de las Administraciones Públicas y de los operadores comerciales debido a una mejor utilización de los recursos, es el caso de las VU en los trámites aduanales. ${ }^{13}$

La Organización de las Naciones Unidas para la Educación, la Ciencia y la Cultura (UNESCO) en su informe "Hacia las Sociedades del Conocimiento" 2005, señala: como concepto tiene dimensiones sociales, éticas y políticas mucho más vastas que la Sociedad de la Información; se refiere a ella en plural debido a que hay una intención de rechazar la unicidad del modelo "listo para su uso" que no tenga suficientemente en cuenta la diversidad cultural y lingüística, elemento que le permite al mundo reconocerse en los cambios que están ocurriendo de modo vertiginoso en el siglo XXI. ${ }^{14}$

La Carta Iberoamericana de Gobierno Electrónico (Chile, 2007) reconoce: El uso de las Tic en los órganos de la Administración para mejorar la información y los servicios ofrecidos a los ciudadanos, orienta la eficacia y eficiencia de la gestión pública e incrementa sustantivamente la transparencia del sector público y la participación de los ciudadanos. ${ }^{15} \mathrm{La}$ importancia que para los países de América Latina y Caribe tiene el desarrollo de iniciativas de la VU se reflejan en el informe del estudio del año 2010 patrocinado por el Sistema Económico Latinoamericano y del Caribe "Ventanillas Únicas de Comercio Exterior (VUCE) en América Latina y el Caribe: avances y retos pendientes". ${ }^{16}$

Otro impacto tecnológico que desarrolla la aplicación de las Tic HA SIDO en la economía digital a través de las nuevas capacidades de la infraestructura de Internet y las potencialidades de las tecnologías como el Cloud computing, Big Data, Internet de las Cosas (IoE), Smart Cities, Industria 4.0. Estos elementos se articulan con estudios desde un enfoque interdisciplinario y transdisciplinario, acoplados desde la combinación de las Ciencias Empresariales y de la Educación, y con contenidos de las Ciencias Jurídicas y Sociales con otros saberes, considerado como el primer contacto con las Tic. ${ }^{17}$

13 CLAD-ONU (2007) Carta Iberoamericana de Gobierno Electrónico. Chile.

${ }^{14}$ UNESCO (2005) Hacia las sociedades del conocimiento. Informe Mundial, Editorial UNESCO, Paris.

15 Piana, R. (2010) La Carta Iberoamericana de Gobierno Electrónico. Orientaciones y buenas prácticas. Democracia Electrónica. Universidad de Zaragoza. España.

16 UNESCO (2013) Enfoques Estratégicos sobre las TICS en América Latina y el Caribe. Oficina Regional de Educación para América Latina y el Caribe, Santiago de Chile.

17 Véase, Antúnez Sánchez, A. (2018) La formación ambiental mediada por el uso de las Tic. Repensando la innovación educativa, Editorial Universidad de Valencia, 
La ONU, en documento de trabajo sustentó que el gobierno electrónico es un pilar en la construcción de un marco estratégico de desarrollo sostenible para los Estados. El uso de la gobernanza electrónica dentro de las naciones puede ser la clave para alcanzar la integración de las metas económicas, sociales y ambientales en la planificación del desarrollo del siglo XXI para el desarrollo sostenible como principio del Derecho Ambiental Internacional reconocido en textos constitucionales. Por ello, en la medida que el sector público continúe reformando las instituciones y los procesos estructurales para aumentar la eficacia y mejorar la prestación de servicios dentro del E-Goverment se creará un ambiente propicio para los negocios y ofrecerá más oportunidades de participación a la ciudadanía. El gobierno electrónico se convertirá gradualmente en el ente activador clave del desarrollo sostenible. ${ }^{18}$

Lo sistematizado, permite aseverar que para la ONU el objetivo del gobierno electrónico es establecer mejores procesos y sistemas para lograr una mayor eficacia, efectividad, inclusión y sostenibilidad por parte de las Administraciones Públicas en su relación con la ciudadanía. La UNESCO le ha reclamado a los Estados a que se le preste especial interés en lograr un mayor acceso a la información de dominio público en un contexto mundial; para ello es necesario concebir estrategias para superar los obstáculos económicos al acceso, potenciar el derecho a la comunicación y el reconocimiento de uso legítimo de la información, así como la utilización eficaz de las telecomunicaciones y de la circulación de la información en la educación, la ciencia y la cultura. ${ }^{19} \mathrm{El}$ gobierno electrónico para la ONU en el uso de las Tic por parte de las instituciones de gobierno señala mejorar cualitativamente los servicios e información que se ofrecen a los ciudadanos, aumentar la eficiencia y eficacia de la gestión pública dentro de sus principios de actuación, así como para incremen-

España; Procedia Cirp (2014) Industry 4.0. The new industrial revolution. How Europe will succeed. Hg V Roland Berg. Strategy Consult. GmbH, Münich; Tascón, M. (2013) Big Data: Pasado, presente y futuro. Editorial Telos. España; Pintos, C. (2012) Open Data, reutilización de la información pública para crear una nueva empresa, Editorial Netbiblo, España; Fernández Aller, C. (2012) Algunos retos de la protección de Datos en la sociedad del conocimiento. Especial detenimiento en la computación en nube (cloud computing), Revista de Derecho UNED, No. 10, España.

18 Piana, R. (2010) La Carta Iberoamericana de Gobierno Electrónico. Orientaciones y buenas prácticas. Democracia Electrónica. Universidad de Zaragoza. España.

${ }_{19}$ Cfr. UNESCO (2013) Enfoques Estratégicos sobre las TICS en América Latina y el Caribe. Chile. 
tar de forma sustantiva la transparencia del sector público y la participación ciudadana. ${ }^{20}$

Se corrobora que las capacidades del sector público para promover la interacción entre el gobierno y la ciudadanía a través de medios virtuales se modifican y están en constate evolución. De esta manera, el desarrollo del E-gobierno constituye otra forma de entender el cambio institucional, donde las capacidades estatales conforman los recursos necesarios para llevar adelante una administración gubernamental del tipo electrónica-relacional con los ciudadanos. La interoperabilidad en la Administración Pública se manifiesta en los diferentes enfoques de relaciones del gobierno electrónico con los administrados, como son el G2G: gobierno a gobierno, G2C: gobierno a ciudadano y G2B: gobierno a empresa.

Son analizadas posturas de autores como Suñe Linas, para quien el Derecho Informático tiene una vertiente de aplicaciones teleinformáticas de directa relevancia para las organizaciones jurídicas (Informática Jurídica) y otra dimensión de Derecho que recae tanto sobre objetos teleinformáticos, como de las cuestiones sociales características de la sociedad de la información. El E-Goverment tiene un marco interdisciplinar, donde se abordan de forma conjunta e integrada cuestiones que son tanto de Informática jurídica (aplicaciones) como de Derecho de la Informática (Derecho). ${ }^{21}$

Galván Ruiz \& García López, razonan que la Administración Electrónica es tan antigua como la informática misma. Refieren que se evidencia con la primera mecanización preinformática, la de máquinas mecánicas que tabulaban tarjetas perforadas, se desarrolló para la elaboración del censo USA de 1890 para la actividad administrativa de estadística pública. La tecnología informática se desarrolló inicialmente al servicio de la Administración Militar en la década de los 60 ' del siglo pasado. ${ }^{22}$

${ }^{20}$ ONU (2012) Estudio sobre Gobierno Electrónico. Departamento de Economía y Asuntos Sociales. Nueva York.

${ }^{21}$ Confróntese, Suñe Llinas, E. (2000) Tratado de Derecho Informático. Introducción y Protección de datos personales, $1^{\mathrm{a}}$ edición, Editorial Universidad Complutense de Madrid, España; Suñé Llinás, E. (2016) ¿Tres o cuatro generaciones de Derechos Humanos? Aporte de claridad conceptual a una feliz ocurrencia. Los Derechos Humanos en el siglo XXI. Editorial Porrúa, México; Suñe Llinas, E. (2016) Derecho informático de las cosas o de segunda generación: El Derecho de la Informática en la $4^{a}$ Revolución Industrial o de la Productividad, Revista Ambiente Jurídico, No. 19, Colombia.

${ }^{22}$ Galván Ruiz, J. \& García López, P. (2007) La Administración Electrónica en España. Editorial Ariel, España. 
Sáez Vacas, reflexiona "Las tecnologías de la información son el último eslabón de la cadena de inventos humanos que va desde el lenguaje hablado, la escritura y la imprenta, hasta nuestros días. El ser humano inventa una tecnología, sea un instrumento material, sea conceptual, y está de vuelta, lo transforma a él". ${ }^{23}$

Delpiazzo, preconiza que el gobierno electrónico es un aspecto genérico que comprende la administración electrónica (e-A) y la democracia electrónica (e-D), siendo aquella básicamente la prestación de servicios públicos y el acceso a los mismos a través de las Tecnologías de la Información y Comunicaciones (Tic). ${ }^{24}$

La CEPAL ha señalado que reconoce que las Tic han favorecido la comunicación instantánea y la globalización. Estar dentro de la red significa estar vinculado desde cualquier lugar del mundo con todos los otros. La diferencia de latitudes y longitudes se anula en el tiempo de la comunicación. Las Tic y los bienes que de ella se derivan son considerados elementos claves para el desarrollo de un país, donde la economía a nivel mundial es digital. ${ }^{25}$

Como se aprecia pervive la diversidad de conceptos en materia de qué es lo que se debe entenderse por gobierno electrónico y donde se debe aplicar para avanzar hacia la democracia digital. Sin embargo, podemos afirmar que todos estos conceptos hacen referencia a una nueva relación, transformada en positivo, entre el Estado y los ciudadanos siendo el gobierno electrónico quien rediseña la gestión pública con miras a mejorar la prestación de servicios al ciudadano como mediador en el uso de las tecnologías. La revolución de las Tic y la evolución demográfica, en especial la urbanización, están descentralizando las estructuras burocráticas de los Estados soberanos. Habrá una mayor participación en la gobernanza de los asuntos públicos, tal y como se concibe por la ONU desde el año 2012. ${ }^{26}$

Dentro de los ordenamientos jurídicos los Estados han regulado esta relación jurídica telemática dentro del Derecho Administrativo

${ }^{23}$ Sáez Vacas, F. (2007) Propuesta personal, basada en la SocioTecnología de la Información y la Cultura: Conviene desarrollar una inteligencia Tecnosocial. Revista Telos, No. 73, España.

${ }^{24}$ Véase, Delpiazzo, C. (2002) Oportunidades y obstáculos del e-commerce, Anuario Derecho Informático, F.C.U. Montevideo; Delpiazzo, C. (2005) Derecho y nuevas tecnologías de la información en los umbrales del siglo XXI, Anuario Derecho Informático, F.C.U. Montevideo.

25 CEPAL (2018) $6^{\text {ta }}$ Conferencia Ministerial sobre la Sociedad de la Información de América Latina y el Caribe: Agenda Digital para América Latina y el Caribe (eLAC2020).

${ }^{26}$ Cfr. Organización de Naciones Unidas (2012) Estudio sobre Gobierno Electrónico. New York. 
a través de una la Ley de Acceso a la Información Pública, convertido en la piedra angular de la democracia digital y además garantiza un mínimo control de los ciudadanos sobre la acción de sus gobernantes, mediante el acceso a la información que el poder político maneja, lo cual guarda relación con el Bid Data, regulado en una Ley de Datos. ${ }^{27}$ El tratamiento legal en la Unión Europea se constata que aparece en la Ley de Acceso Electrónico de los Ciudadanos a los Servicios Públicos. En particular en España, en el Derecho Autonómico han sido añadidos a favor de la consolidación del principio de simplificación como un principio transversal de la actuación de la Administración Pública con los ciudadanos, como lo refrendan desde su posición Gamero Casado, Valero Torrijos, Piñar Mañas, Barnes Vázquez, Bernardí Gil y Palomar Olmeda. ${ }^{28}$

En los Estados Unidos de América, la implementación del E-Government Act establece: Uso por la Administración de aplicaciones basadas en sistemas Web e Internet y otras tecnologías de la información, de forma combinada con procesos para implementar esas tecnologías para permitir el acceso y entrega de información y prestación de servicios al público, a otras agencias y a otras entidades de gobierno; o producir mejoras en las actividades gubernamentales con el objetivo de que puedan aumentar la eficacia, la calidad de los servicios o su transformación.

Con lo citado, se aprecia la interacción que existe entre las Tic y la gestión pública de las Administraciones Públicas, así como al proceso de las políticas públicas que ejecutan al constituir uno de los pilares básicos en el campo de acción del E-gobierno. Donde aspectos como el liderazgo, la gestión del capital humano, el diseño y cam-

${ }^{27}$ Consúltese, Pérez Luño, A. (2000) La seguridad jurídica. Boletín de la Facultad de Derecho No. 15, UNED, España; Morcillo Moreno, J. (2005) La Identidad Digital, mediante el documento nacional de identidad electrónico. Administraciones Públicas y Nuevas Tecnologías. Editorial Lex Nova. España; Martín Delgado, I. (2009) Naturaleza, concepto y régimen jurídico de la actuación administrativa automatizada, RAP, N. 180, España; Oliver Cuello, R. (2009) La regulación de la administración electrónica tributaria, Administración Electrónica Tributaria, Editorial Bosch, Barcelona; Mira Ros, C. (2010) El expediente judicial electrónico, Editorial Dykinson, Madrid.

${ }_{28}$ Confróntese, Gamero Casado, V. y Valero Torrijos, J. (2009) Ventanilla Única y Administración Electrónica en la transposición de la Directiva de Servicios, $2^{\mathrm{a}}$ edición, Universidad Pablo de Olavide, Sevilla; Barnés Vázquez, J. (2000) Una reflexión introductoria sobre el Derecho Administrativo y la Administración Pública de la Sociedad de la información y del conocimiento, Revista Andaluza de Administración Pública, $\mathrm{N}^{\circ}$ 40, España; Palomar Olmeda, A. (2007) La actividad administrativa efectuada por medios electrónicos, Navarra; Bernadí Gil, X. (2005) Derecho Público y Administración electrónica: una visión panorámica. Nuevas políticas públicas. Anuario multidisciplinar para la modernización de las Administraciones públicas, $\mathrm{N}^{\mathrm{o}} 1$, España. 
bio organizativo, las relaciones interadministrativas e intergubernamentales, la comunicación y el marketing de los servicios, así como la transparencia no se pueden ni se deben entender de la misma manera en un entorno en el que las Administraciones Públicas son usuarias de las Tic en esta relación telemática que se conforma. En el tratamiento se pondera el cumplimiento del principio de información con la aplicación de las Tic y se está en presencia además de los tópicos de la descarga burocrática y la simplificación de la intervención administrativa sobre la actividad de los particulares y personas jurídicas con el fin de agilizar la actuación de las Administración Pública con respeto al principio de legalidad.

En la región del Caribe, la Declaración de Santo Domingo sobre Gobernabilidad y Desarrollo en la Sociedad del Conocimiento de la Organización de Estados Americanos, subraya la importancia que desempeñan las Tic como herramienta transversal para el logro del desarrollo equitativo y sostenible y el fortalecimiento de la gobernabilidad. En este documento se estableció el compromiso de los Estados miembros de incorporar las Tic en sus planes nacionales de desarrollo, particularmente en los procesos de modernización de las instituciones públicas, para entre otros temas, propiciar la eficiencia en la gestión y la provisión de servicios en el sector público, así como dedicar especial énfasis a la modernización del Estado a través del diseño e implementación de estrategias de gobierno electrónico con el fin de mejorar la provisión de servicios e información a la población en su conjunto. ${ }^{29}$

La digitalización de la información está permitiendo crear nuevas formas de codificación, representación y construcción de la cultura en las que las experiencias analógicas a menudo se confunden con las virtuales, propiciando un ida y vuelta entre estos dos escenarios de interacción sociocultural, y evidenciando que, en las últimas décadas, la influencia de los medios de comunicación no ha ido a la par del fomento de la alfabetización mediática. ${ }^{30} \mathrm{El}$ gobierno elec-

${ }^{29}$ Véase, Criado, J. (2009) Gobierno electrónico en Latinoamérica: Aproximación desde una perspectiva intergubernamental, Estado, Gobierno, Gestión Pública. Revista Chilena de Administración Pública, No. 14, Chile; CEPAL/ONU (2007) Libro Blanco de Interoperabilidad de Gobierno Electrónico para América Latina y el Caribe. Versión 3.0. United Nations Publications. Ginebra; OMC (2015) Revisión y análisis de la aplicación del Acuerdo de la Organización Mundial del Comercio (OMC) sobre Facilitación del Comercio en Países de América Latina y el Caribe (ALC), SELA, Venezuela.

${ }^{30}$ Consúltese, Rivero Ortega, R. (2007) El Expediente Administrativo. De los Legajos a los Soportes Electrónicos. Editorial Thomson-Aranzadi. Navarra; Ugalde, V. (2004) Sobre la digitalización de trámites en la transición al e-gobierno, Revista Gestión y Política Pública, No 1, España, pp. 41-80. 
trónico proyecta impactar en la transparencia de la gestión pública, en pos de mejorar la información divulgada por la Administración Pública. "Transparencia, en términos generales, significa conducir las actividades de una manera en que las decisiones, las reglas y otra información se hacen visibles desde el exterior". En la sociedad contemporánea ningún agente se muestra contario, a priori, a la transparencia. ${ }^{31}$ Para hacerlo operativo y contrastable se plantea que: “...la transparencia en la sociedad de nuestros dias significa información fácilmente accesible, fiable, que sea relevante para las decisiones, que resulte comparable y que se presente de forma clara y oportuna. En definitiva, que cumpla los requisitos y características cualitativas del marco conceptual de la contabilidad, con un especial énfasis en la accesibilidad, derivado del papel revolucionario del internet..." 32

El uso por la Administración Pública de aplicaciones basadas en los sistemas web en Internet y otras herramientas de las Tic de forma combinada con otros procesos para implementar estas tecnologías, permiten el acceso y entrega de información y prestación de servicios al público a otras agencias y a otras entidades de gobierno; con ello se producen mejoras en las actividades gubernamentales con el objetivo de que puedan aumentar la eficacia, la calidad de los servicios o su transformación. Ello ofrece la oportunidad de dar nueva vitalidad a los gobiernos, pero también es necesario favorecer la participación del ciudadano en la gestación de políticas públicas y en los procesos de gobernanza. ${ }^{33}$ Exige a la Administración Pública para la implementación del E-Goverment de una serie de requisitos que tienen que ponderar la seguridad técnica y jurídica. Su regulación jurídica se establece en la Ley de Procedimiento de la Administración Pública, en la Ley para el reconocimiento de la Firma Electrónica, destinada a la firma digital. Estos cuerpos jurídicos dan lugar a una relación jurídica telemática con la Administración Pú-

${ }^{31}$ Confróntese, Hood, C. (2010) ¿Accountability and Transparency: Siamese Twins, Matching Parts, Awkward Couple? West European Politics, No. 5, pp.9891009; Leal, B. (2016) Planificación, colaboración y autocontrol: nuevos instrumentos normativos para la administración fiscalizadora. Revista de Derecho Público, $\mathrm{N}^{\circ} .83$, Chile, pp. 105-122; Junceda Moreno, J. (2016) Obligaciones sobre transparencia. Protección de datos. Sobre los límites de la transparencia en el ámbito local. La Administración Práctica, No. 8, España. pp. 55-61.

${ }^{32}$ Montesinos, V. (2009) Transparencia y responsabilidad en el sector público: el papel de la información en tiempos de crisis. Revista AECA №.87, España, pp.26-28.

33 Véase, Camacho, G. (2000) Los principios de eficacia y eficiencia administrativa, Editorial Conosur, Argentina; Santamaría Pastor, J. (2009) Principios de Derecho Administrativo, Editorial Iustel, España; Rivero Ortega, R. (2010) Principio de celeridad. Los principios jurídicos del Derecho Administrativo, Editorial La Ley, Madrid. 
blica con una Ley de Datos incidente en el tratamiento de los datos de los ciudadanos. Se constata como guarda relación con el Derecho Laboral (Teletrabajo) ${ }^{34}$, con el Derecho Marítimo con la digitalización de las actividades en puertos y en la navegación. Otro de sus usos es la Votación Electrónica (E-vote), primer escalón de la Democracia-E, como lo refieren desde sus estudios Arena, Cruz Rivero, Cotino Hueso, Barriuso Ruiz, y Blasco Díaz. ${ }^{35}$ Otros de los usos que en el siglo XXI es el de dinero electrónico (Bitcoin), esto cambia las relaciones comerciales y necesita de una regulación jurídica: es un hecho nuevo en las relaciones monetario mercantiles. ${ }^{36}$

Lleva a considerar que el paradigma papel hoy convive con el paradigma digital, gestionado en sistemas híbridos de información. La documentación soportada en papel puede ser convertida con facilidad en objetos digitales derivados y ser gestionados para su preservación y acceso como mismo sucede con los objetos digitales originarios al ser parte del Patrimonio Digital, el cual dentro de las políticas públicas de los Estados ira sustituyendo al papel en correspondencia con la preservación ambiental. Las soluciones mediadas por el fomento del gobierno electrónico por la Administración Pública, se pondera que lleva implícito superar la visión de clientes digitales a ciudadanos, en áreas como la política, la económica y la social desde la impronta digital. Estas soluciones tienen que estar destinadas a facilitar la vida de la comunidad al constituir ahorros en los gastos públicos y permitir el aumento de la eficiencia y la transparencia en la gestión de la Administración Pública para con los ciudadanos y empresarios (Ventanilla Única Empresarial). De aquí la necesidad de ponderar en los procesos que se ejecutan entre la Administración Pública y los ciudadanos el fomento de la VU, ello

${ }^{34}$ Consúltese, Ortiz Chaparro, F. (1995) El Teletrabajo. Una Nueva Sociedad Laboral en la Era de la Tecnología. Editorial McGraw \& Hill. España; Antúnez Sánchez, A. (2008) El teletrabajo en Cuba. №. 51. Revista Federal del Trabajo, Argentina.

35 Confróntese, Arena, G. (2004) E-Government y Nuevos Modelos de Administración. Revista de Administración Pública N 163, España; Cruz Rivero, D. (2006) El DNI Electrónico y el Mercado de las Entidades de Certificación. Revista de Contratación Electrónica. N ${ }^{\circ}$ 69, España; Cotino Hueso, L. (2006) El Voto Electrónico o la Casa por el Tejado. La Necesidad de Construir la Democracia y Participación Electrónicas por los Cimientos. Libertades, Democracia y Gobierno Electrónicos. Editorial Comares, Granada; Barriuso Ruiz, C. (2007) Administración electrónica, Editorial Dykinson, Madrid; Blasco Díaz, J. (2008) Los derechos de los ciudadanos en su relación electrónica con la Administración. Derechos fundamentales y otros estudios, Editorial Justicia de Aragón, Zaragoza.

${ }^{36}$ Martino, A. (2015) Sociocibérnetica, Informática Jurídica e Infoética. Buenas prácticas y Lecciones aprendidas. Editorial UNIJURIS, Cuba. 
será analizado up supra su definición, función, contenido, aplicación y clasificación. ${ }^{37}$

\subsection{La Ventanilla Única. Definición, función, contenido, aplicación, clasificación y naturaleza jurídica}

La VU es considerada como un instrumento unitario e integral para satisfacer de manera plena el propósito perseguido con la utilización de las Tic. No es tan sólo un instrumento funcional, es un mecanismo visualmente para el usuario que pretende identificarle un interlocutor único con el que realizar todos los trámites que precise y al que solicitarle toda la información que necesite, de aquí que se conciba su naturaleza jurídica. A pesar de tratarse de un mero instrumento de información por vía telemática (constituye el nivel primario o elemental de administración electrónica) articulado en un centro único de información. Está soportada tanto por un sistema de información como por un sistema de tramitación. ${ }^{38}$ La primera funcionalidad de la VU consiste en erigirla en una fuente de información administrativa general sobre los requisitos exigibles al prestador para el inicio de la actividad de servicios. Se trata de información administrativa general, no particular: la VU no se convierte en un asesor técnico del prestador que le orienta acerca del mejor modo para atender las exigencias administrativas en su concreto caso, ni tampoco se configura como un instrumento de acceso de los interesados al estado de tramitación de un expediente administrativo relativo al inicio de una actividad de servicios. ${ }^{39}$

La VU está concebida como una aplicación concreta de los conceptos de facilitación del comercio que permite reducir los obstáculos no arancelarios al comercio. Fue concebida como un servicio que permite a los operadores comerciales presentar la información y documentos en un solo punto de entrada a fin de satisfacer los requisitos normativos relacionados con la importación, exportación y el tránsito. Sin la información es electrónica, los elementos de datos

${ }^{37}$ Para ello, véase, Gamero Casado, E. (2009) Interoperabilidad y administración electrónica: conéctense, por favor, RAP, No 179, España, p.291 y ss; Cerrillo Martínez, A. (2008) La Ley de Administración electrónica. Comentario sistemático a la Ley 11/2007, de 22 de junio, de acceso electrónico de los ciudadanos a los Servicios Públi$\cos$, Editorial Aranzadi, Navarra.

${ }^{38}$ Cfr. Suñé Llinás, E. (2004) La Ventanilla Única Electrónica. Actas del X Congreso Iberoamericano de Derecho e Informática. Centro de Estudios en Derecho Informático, Chile.

${ }^{39}$ Cfr. Arena, G. (2004) E-Government y Nuevos Modelos de Administración. Revista de Administración Pública $\mathrm{N}^{\mathrm{o}} 163$, España.

(C) UNED. Revista de Derecho UNED, núm. 25, 2019 
específicos solo se deberían presentar una vez. No implica, necesariamente, la aplicación y el uso de Tic sofisticadas, aunque el servicio mejora considerablemente si los gobiernos identifican e implementan las Tic apropiadas para ese fin. ${ }^{40}$

Se han realizado por los Estados medidas para simplificar los actos administrativos con las herramientas que aportan las Tic en una arquitectura digital eficiente, ejemplo de lo acotado aparece en instrumentos adoptados en la Unión Europea a tenor del "Libro Verde Menos trámites administrativos para los ciudadanos: promover la libre circulación de los documentos públicos y el reconocimiento de los efectos de los certificados de estado civil (2010)"41, aquí se pondera el principio de celeridad. Sin menoscabar otros principios informadores del proceso de simplificación y racionalización de los procedimientos que se persigue con la implementación de la VU como: la eficacia y eficiencia; la economía procedimental; la transparencia administrativa y el servicio efectivo a los ciudadanos. ${ }^{42}$

Con la VU la sistematización constituye un primer paso para facilitar los trámites al ciudadano, es colocar en una plataforma digital nacional los datos abiertos para mejorar la gestión pública en la modernización del Estado en el siglo XXI incidentes en la mejora de los servicios públicos, aumentar la integridad pública, la transparencia, la rendición de cuentas y la participación ciudadana, así como administrar los recursos públicos con mayor eficacia. De aquí que su naturaleza sea un instrumento funcional. Un mecanismo visualmente unitario para el usuario que pretende identificarle un interlocutor único con el que realizar todos los trámites que precise y al que solicitarle toda la información que necesite. ${ }^{43}$

${ }^{40}$ Salazar Solís, L. (2006) Ventanilla única de gobierno electrónico. Colección documentos de trabajo sobre e-Gobierno. Red de Líderes de Gobierno Electrónico de América Latina y El Caribe. Chile.

${ }^{41}$ Comisión Europea (2010) Libro Verde. Menos trámites administrativos para los ciudadanos: promover la libre circulación de los documentos públicos y el reconocimiento de los efectos de los certificados de estado civil, Bruselas.

${ }^{42}$ Confróntese, Valero Torrijos, J. (2000) Administración Pública, ciudadanos y nuevas tecnologías. El Derecho Administrativo en el umbral del siglo XXI. Editorial Tirant lo Blanch, Valencia; Sancho Royo, D. (2005) Sociedad de la información y gobierno, Instituto Andaluz de Administración Pública, Sevilla; Montesinos, V. (2009) Transparencia y responsabilidad en el sector público: el papel de la información en tiempos de crisis. Revista AECA No.87, España, pp.26-28; Robles Morales, J. (2009) Ciudadanía digital: una introducción a un nuevo concepto de ciudadano. Editorial UOC, Barcelona; Pérez Luño, A. (2014) Teledemocracia, ciberciudadania y derechos humanos, Revista Brasilera de Políticas Públicas, No.2, Brasil.

${ }^{43}$ Gamero Casado, E. (2009) Ventanilla única y administración electrónica en la transposición de la directiva de servicios, Universidad Pablo de Olavide de Sevilla. 
Cancino Gómez, Witker y Trejo Vargas, consideran que la VU en el comercio exterior su finalidad es que se reduzcan los tiempos de trámite, se abatan costos y se acoten lo nichos de poder, facultando y determinando quiénes operarán la infraestructura tecnológica para que existan procesos horizontales con trámites en tiempo y forma, definiendo el esquema electrónico avalado por las organizaciones internacionales de tal forma que permita a los comerciantes, presentar la documentación y/o información exigidas para la importación, la exportación o el tránsito de mercancías en un punto de entrada único. Su reconocimiento legal parte de los acuerdos de la OMC en materia de Aduanas de 1988 y se desarrolla en el ordenamiento jurídico mexicano. ${ }^{44}$

La CEPAL señala que los contenidos de funcionalidad están vinculados a la implementación y al uso de la VU (el suministro de información administrativa general) son relativamente fácil de articular en la arquitectura donde se diseñe. Supone únicamente la necesidad de inventariar los trámites que exige el inicio de una actividad de servicios en las diferentes Administraciones Públicas, recopilando para ello la información mediante alguna herramienta estandarizada, y articular un medio para su integración en un solo portal de Internet desde el que los interesados puedan descargar la información, lo cual puede llevarse a cabo mediante un simple cribado o screening. ${ }^{45}$

Vinculado con el E-goverment está el "El Portal Ciudadano", al ejecutar el intercambio de información entre el Gobierno y el ciudadano. Su clasificación se concibe en tres conceptos básicos al implementarse por la Administración Pública una VU a través de: las ventanillas informativas, las ventanillas de punto de enlace, y las ventanillas transaccionales. Dentro del Sistema de Naciones Unidas se ha considerado que las VU pueden ser reconocidas tanto en la modalidad física como la electrónica. Su evolución en el siglo XXI está siendo fomentada a través de aplicaciones (APK) en los móviles Inteligentes, denominado M-Government, es la tecnología personal

${ }^{44}$ Véase, Cancino Gómez, R. (2015) Análisis jurídico de la Ventanilla Única de comercio exterior, Revista Jurídica UNAM, México; Trejo Vargas, P. (2012) Naturaleza del acto administrativo y del despacho aduanero electrónicos o digitales, México y el comercio exterior, Revista Novum, México; Witker, J. (2010) Régimen jurídico del comercio exterior, Editorial MPc editores, México, p. 124.

45 CEPAL (2018) $6^{\text {ta }}$ Conferencia Ministerial sobre la Sociedad de la Información de América Latina y el Caribe: Agenda Digital para América Latina y el Caribe (eLAC2020. Chile); Naser. A. et al. (2011) El gobierno electrónico en la gestión pública, CEPAL, Chile; ONU (2012) Estudio de las Naciones Unidas sobre el Gobierno Electrónico, Nueva York. 
más extendida y la de más rápida difusión de la información entre los ciudadanos. Tiene la ventaja de ser una tecnología vinculada a la persona, lo que facilita la verificación de la identidad y localización del que la usa, abre más posibilidades de personalización de los servicios públicos que se prestan. El uso de móviles inteligentes ha influido en la democratización del acceso a Internet y al incremento en el número de usuarios y dispositivos conectados. Marcado por la aparición de los dispositivos móviles inteligentes, pequeños ordenadores de mano capaces de comunicarse y conectarse a Internet con la miniaturización de la tecnología. Esta revolución de dispositivos móviles conectados a la red ha sido posible gracias a los avances realizados en el campo de la miniaturización de la informática. Los avances en el campo de la miniaturización han extendido la posibilidad de crear objetos con capacidades para el incremento de usuarios y dispositivos conectados a Internet, y la otra el crecimiento de los datos que generan estos dispositivos. ${ }^{46}$

Lo que permitirá analizar up supra cómo ha sido el reconocimiento jurídico dentro del Derecho Ambiental de la Ventanilla Única de Certificación Ambiental en el E-Goverment como un principio ciudadano vinculada al principio 10 de la Declaración de Río sobre el Medio Ambiente y el Desarrollo de 1992 sobre la información ambiental.

\subsection{La Ventanilla Única de Certificación Ambiental dentro del E-goverment}

Para su análisis, tenemos en consideración la postura de Canals Ametller, quien refiere que la tramitación por medios electrónicos tiene como ventajas evitar el exceso de trámites, reducir la carga documental y el factor tiempo en los procedimientos administrativos (tanto para los interesados como para los órganos administrativos), así como la consiguiente racionalización administrativa, pero no es, en sentido estricto, un medio de simplificación administrativa sino más bien un mecanismo cuya aplicación práctica permite obtener esas ventajas. ${ }^{47}$

46 Rossel, P. et al. (2006) Mobile' E-government Options: Between Technologydriven and User-centric. The Electronic Journal of E-government, $\mathrm{N}^{\circ}$. 2, pp. 79-86.

${ }^{47}$ Cfr. Canals Ametller, D. (2012) Simplificación administrativa y directiva de servicios: objetivos, medios e incidencias, el procedimiento administrativo: descarga burocrática, INAP, España. 
Guillén Caramés, considera que las nuevas tecnologías de la información y la comunicación seguirán entrando en nuestras vidas hasta niveles imposibles de predecir, pero poco sabemos acerca de que tecnologías concretas y como operarán. También sabemos que el mundo en el que hoy vivimos sería impensable sin las tecnologías de la información y la comunicación. Ni los mercados financieros, ni la sanidad, ni la educación, ni las relaciones entre las empresas serían como son, pero poco sabemos de cómo serán en el futuro. Una de las pocas certezas que tenemos en relación con la administración electrónica es que acabará determinando los modos de relación de los ciudadanos con las instituciones públicas de una manera radicalmente distinta a como son hoy y sin duda, alterando de forma profunda el sistema de derechos, garantías y obligaciones de unos y otras. Uno de los últimos impulsos en esta materia ha sido la nueva Ley de Acceso Electrónico de los Ciudadanos a los Servicios Públicos. ${ }^{48}$

En el Derecho Ambiental Europeo se pondera dentro de la gestión ambiental integrada dentro de la modernización de la gestión pública con la inclusión de la Evaluación Ambiental Estratégica al usar las Tic. Aquí hay una amplia gama de instrumentos de gestión ambiental como: los de planificación, promoción, prevención, control, corrección, información, financiamiento, participación, fiscalización, ordenamiento territorial, estándares de calidad ambiental, límites máximos permisibles, certificación ambiental, plan de prevención, etc. La VU debe ser accesible los 7 días de la semana de las 24 horas del día. Analizadas estas posturas y su reconocimiento jurídico, se considera que la VUCA permite una relación jurídica telemática dentro del gobierno digital abierto para la protección ambiental. ${ }^{49}$

En América Latina, es reconocida en los ordenamientos jurídicos vinculada con las herramientas de gestión ambiental, en particular con la ejecución de procesos de Evaluación de Impacto Ambiental (EIA). ${ }^{50}$ La Ventanilla Única de Certificación Ambiental (VUCA)

48 Guillén Caramés, J. (2010) La Administración Electrónica: ¿Mito o realidad para los ciudadanos del siglo XXI?, Centro PwC \& IE del Sector Público, Madrid.

${ }^{49}$ Véase, Antúnez Sánchez, A. (2016) La gestión ambiental. Incidencia en el comercio, Revista Veredas Do Direito Ambiental e Desenvolvimiento Sustentavel, $\mathrm{N}^{\circ}$ 26, Brasil; Antúnez Sánchez, A. (2018) La fórmula estimulación/recompensa en el Derecho Administrativo Ambiental. Visión desde la administración estratégica por los sujetos de gestión. Revista de Investigación y Análisis De Jure, México.

50 Confróntese, Font Llovet, T. (1994) Instrumentos jurídicos en la protección del medio ambiente, Revista Aragonesa de Administración Pública, №. 5, España, p. 50; Martín Mateo, R. (1997) Derecho Administrativo Ambiental, $6^{\text {ta }}$ edición, Editorial 
es considerada un mecanismo de gobierno electrónico creado por la Administración Pública para el desarrollo de los procedimientos de certificación ambiental en los EIA, los Registros Ambientales, el acceso a la Información Ambiental y a otros procedimientos administrativos ambientales que se le incorporan progresivamente a través de una plataforma virtual creada como consulta de los ciudadanos. 51

Aldana Duran, considera que la VUCA es un mecanismo de gobierno electrónico para el desarrollo de procedimientos de certificación ambiental de la EIA-d, los registros ambientales y otros procedimientos administrativos ambientales que se incorporen progresivamente. Debe permitir la gestión de la información ambiental relevante en materia de EIA, para que con ello se permita adoptar las medidas que correspondan. Se ha reconocido en los ordenamientos jurídicos en la Ley Marco Ambiental y en la Ley de EIA en Perú, Colombia, Chile, Ecuador, México, en pos de prestarse un mejor servicio al ciudadano en un gobierno digital abierto dentro del Derecho Ambiental Latinoamericano. ${ }^{52}$

La VUCA debe permitir la gestión de información ambiental relevante en materia de EIA, siendo a criterio de los autores uno de sus nexos vinculantes. Su diseño conceptual a partir del cual se habrá de formular la arquitectura informática requerida para su implementación, requiere avanzar en diversos frentes de manera integrada para lograr el objetivo de llegar a contar con la herramienta eficiente y que esta se utilice de manera exitosa para alcanzar su finalidad última de mejorar los servicios al ciudadano en materia de permisos ambientales otorgados por la Autoridad Ambiental. ${ }^{53}$

Trivium, España; Parejo Alfonso, L. \& Alfonso D. (2012) Autorizaciones y Licencias, Hoy, Editorial Tirant lo Blanch, España; Embid Irujo, A. (2012) La Evaluación de impacto ambiental en la Unión Europea. Revista de Justicia Administrativa. No 57. España; Antúnez Sánchez, A. et al. (2018) La inspección ambiental. La evaluación de impacto ambiental. La autorización ambiental y la auditoría ambiental, Revista Excelencia Administrativa, № 38, México.

51 Aldana, M. (2016) Caminando hacia la ventanilla única de certificación ambiental, Revista Circulo de Derecho Administrativo, Perú; Comunidad Andina (2016) Implementación de Ventanillas Únicas de Comercio Exterior en los países de la comunidad andina.

${ }^{52}$ Cfr. Aldana Duran, M. (2016) Caminando hacia la ventanilla única de certificación ambiental, Perú.

${ }_{53}$ Véase, Galindo, F. (2006) Gobierno, Derecho y Tecnología: Las actividades de los Poderes Públicos. Editorial Thomson Civitas, España; Manchado, A. (2010) Gobierno abierto: una aproximación desde el Estado. Open Government: Gobierno abierto, Editorial Algón, España; Canals Ametller, D. (2012) Simplificación administrativa y directiva de servicios: objetivos, medios e incidencias, el procedimiento administrativo: descarga burocrática, INAP, España. 
Con la implementación de la VUCA todos los problemas existentes en la ejecución de la EIA no van a ser resueltos. En todo caso, sí debe entenderse a esta herramienta de gestión ambiental como un medio a utilizar para optimizar el procedimiento administrativo en beneficio del usuario del servicio, así como también en beneficio de la población del país que ve la EIA como un medio útil para la prevención de daños ambientales y de los conflictos ambientales que pueda producir. ${ }^{54}$ Se valora como se realizan procedimientos administrativos en línea mediado por los medios electrónicos, cuyos resultados deben contener equivalencia legal a los procedimientos que se realizan en físico. A tales efectos, se hace necesario que tanto los usuarios como el proveedor del servicio de la VUCA hagan uso de las herramientas legales existentes en materia de gobierno electrónico, ponderándose a criterio de los autores del artículo el principio de legalidad.

En esta misma cuerda, la Directiva de Servicios N ${ }^{\circ} .205$ de 2004 del Parlamento Europeo como política pública mantiene una cierta preocupación por hacer efectivo el principio de reciprocidad y cooperación administrativa entre los Estados miembros. Sostiene que a los efectos de una mayor simplificación de los procedimientos administrativos conviene garantizar que todo prestador de servicios disponga de un interlocutor único -o ventanilla única- al que dirigirse para realizar los procedimientos y trámites preceptivos. La finalidad primordial de las VU es ayudar al prestador de servicios «ya sea como autoridad directamente competente para expedir los documentos necesarios para acceder a una actividad de servicios, ya sea como intermediario entre el prestador y dichas autoridades directamente competentes» En correspondencia con el E-goverment la Ley $\mathrm{N}^{\circ} .11$ de 2007 reconoce como principio general al que ha de ajustarse la utilización de las tecnologías de la información el principio general de simplificación administrativa «por el que se reduzcan de manera sustancial los tiempos y plazos de los procedimientos administrativos, logrando una mayor eficacia y eficiencia en la actividad administrativa ${ }^{55}$

${ }^{54}$ Cfr. Aldana, M. (2016) Caminando hacia la ventanilla única de certificación ambiental, Perú.

${ }_{55}$ Confróntese, Palomar Olmeda, A. (2008) Gestión electrónica de los procedimientos. La Ley de Administración Electrónica. Comentario sistemático a la Ley 11/2007 de Acceso Electrónico de los Ciudadanos a los Servicios Públicos, Editorial Aranzadi, Cizur Menor; Punzón Moraleda, J. et al. (2009) La utilización de medios electrónicos, informáticos y telemáticos en la Ley 30/2007, de contratos del Sector Público, La Ley, Editorial Las Rozas, España; Sánchez Sánchez, Z. (2009) Administración electrónica y Directiva de Servicios: ¿al servicio del mercado o paradigma de 
Aquí los certificados digitales permiten la identificación de una persona a través de un documento electrónico generado y firmado digitalmente por una entidad de certificación con la Firma Digital, firma electrónica que utiliza una técnica de criptografía asimétrica, permite que las personas que conocen la clave pública no puedan derivar de ella la clave privada a los efectos de lograr un procedimiento administrativo con el menor costo posible en términos de tiempo, por ello es recomendable contar con el sistema de pagos del respectivo procedimiento incorporado en el sistema virtual la VUCA. Para la seguridad de la información es de importancia como objeto de transferencia de información o de pagos de servicios a través del sistema para reducir la vulnerabilidad ante amenazas que puedan poner en riesgo la integridad y la seguridad. ${ }^{56}$ De aquí que la VUCA tiene nexo con el Reglamento de la Ley de Firmas y Certificados Digitales, donde todo ciudadano tiene derecho al acceso a servicios públicos para la realización de transacciones de gobierno electrónico con las entidades de la Administración Pública como manifestación de su voluntad, a través de medios electrónicos seguros. ${ }^{57}$

\section{LA VENTANILLA ÚNICA DE CERTIFICACIÓN AMBIENTAL EN EL GOBIERNO DIGITAL EN CUBA}

\subsection{El E-Goverment en Cuba}

Amoroso, refiere en sus estudios que la utilización de las Tic en Cuba por parte de la Administración Pública se remonta al final de la década del 20' del pasado siglo con la introducción de los primeros equipos destinados al procesamiento de datos para desarrollar el censo de población ejecutado en el año 1930. Después al decursar del tiempo la Compañía IBM instala en La Habana una sucursal con rango de oficina central para el Caribe y la América Central. Desde entonces, puede afirmarse que la utilización de equipos informáticos aumentó considerablemente, de modo especial en las empresas con

buena administración?, Mercado europeo y reformas administrativas. La transposición de la Directiva de Servicios en España, Editorial Civitas, Navarra.

56 Véase, Cruz Rivero, D. (2005) Análisis de los Antecedentes del Concepto de Firma Electrónica como Equivalente a la Firma Manuscrita. Revista de Contratación Electrónica No 60, España; Valenzuela Rivera, M. (2007) Firma digital. Consideraciones jurídicas, Revista Jurídica, Universidad San Carlos, Guatemala; Oliver Cuello, R. (2009) La regulación de la administración electrónica tributaria, Administración Electrónica Tributaria, Editorial Bosch, Barcelona.

57 Delpiazzo C. (2001) Adecuación del Derecho a la necesidad de la firma electrónica, Informática y Derecho: Aportes de doctrina internacional, Editorial Depalma, Buenos Aires. 
capital norteamericano radicadas en Cuba. Cabe recordar que en este tiempo el potencial informático se concentraba en La Habana, capital de la República de Cuba. Esta etapa se caracteriza por el predominio de la introducción de equipos electromecánicos de procesamiento de información en tarjetas perforadas, además del establecimiento de un monopolio que consistía no sólo en la producción y venia de los equipos que se introducían, sino también de la reparación y el mantenimiento de los mismos, así como de los servicios de diseño e implantación de los sistemas que se aplicaban, e incluso los especialistas. Con el triunfo de la Revolución en 1959, la situación cambió. El gobierno introdujo en el país computadoras electrónicas de la primera generación. Luego, en 1965 adquirió computadoras de la segunda generación para el cálculo científico y la formación de especialistas informáticos. ${ }^{58}$

Con el proceso de institucionalización en el análisis del tracto histórico, en la nación se previó el desarrollo de instituciones en las funciones de dirección y aplicación de las políticas trazadas. Así, dentro del ordenamiento jurídico cubano con la promulgación de la Ley $\mathrm{N}^{\circ} .1323$ de 1976, se crea el Instituto de Sistemas Automatizados y Técnicas de Computación (INSAC) de conformidad con lo establecido en el artículo 86, Decreto Ley Nº 67 de 1983 dentro de la Administración Pública. Con la entrada de Cuba a Internet se había llegado a consenso gubernamental de cuál debía ser la estrategia cubana de acceso y transmisión de datos, para impedir que la isla se convirtiera en consumidora pasiva de conocimientos en pos garantizar su seguridad informática y la veracidad de la información que se difundiera. El Decreto Ley No. 209 de 1996, priorizaba el enlace de las personas jurídicas y las instituciones de mayor relevancia en el país y establece el ordenamiento al acceso pleno a Internet en la República de Cuba. ${ }^{59}$

En este tracto jurídico en el 2000, se crea el Ministerio de la Informática y las Comunicaciones (MIC) con la misión fundamental de fomentar el uso masivo de las Tic en la economía nacional, la sociedad y al servicio del ciudadano mediante la estrategia nacional de informatización contenida en el Programa Rector de la Informa-

${ }^{58}$ Cfr. Amoroso Fernández, Y. (2014) Gobierno Electrónico: propuesta metodológica de desarrollo y evaluación, UNAM, México; Amoroso Y. et al. (2018) Gobierno electrónico: reflexiones desde la UIC. Cibersociedad - soñando y actuando. Editorial Futuro, La Habana, pp.155-171.

59 Consúltese, Amoroso Y. et al. (2018) Gobierno electrónico: reflexiones desde la UIC. Cibersociedad - soñando y actuando. Editorial Futuro, La Habana, pp.155-171; Delgado Novoa, M. (2013) Necesidad de una ley de protección de datos personales en Cuba, Observatorio Iberoamericano de Protección de Datos, España. 
tización de la Sociedad en Cuba. "Las Tecnologías de la Información y las Comunicaciones en general, ofrecen oportunidades para que las personas, las organizaciones y las comunidades puedan desarrollar su pleno potencial, promover su desarrollo sostenible y mejorar su calidad de vida." ${ }^{60}$ ETECSA, provee el servicio concesionado de administrar la nube gubernamental, lo hace a través de un Centro de Datos habilitado para tales fines, es la encargada de prestar los servicios públicos a la ciudadanía y a las personas jurídicas. Lo hace en correspondencia con los lineamientos de la Política Económica y Social aprobados en el $7^{\text {mo }}$ Congreso del Partido Comunista de Cuba de 2017, apuntan hacia la racionalización del sistema de trámites en sectores como la vivienda y planificación física (lineamientos 97, 236). En el lineamiento 272 se menciona que el país debe avanzar hacia el mayor nivel de informatización posible de acuerdo a los recursos financieros que se destinen con tales propósitos. ${ }^{61}$

En la Administración Pública nacional los estudios del E-goverment se aprecian desde las ciencias jurídicas y en especial desde el Derecho Administrativo y en la Informática Jurídica, señalan que para implementar una plataforma de gobierno electrónico; primeramente, se debe entender completamente la realidad del contenido del gobierno electrónico. Otros aspectos que se deben examinar, con relación a los beneficios que ofrece el gobierno electrónico, son: analizar si existe una infraestructura tecnológica apropiada disponible; estudiar si la Administración Pública está preparada para servir a los ciudadanos en la era de las Tic; y analizar si existe un marco legislativo que apoye al gobierno electrónico en la nación, como lo han venido reseñado Amoroso Fernández, Delgado, Sánchez Díaz, Ojeda Bello y Formentin Zayas. ${ }^{62}$

Amoroso en este sentido valora que, para alcanzar un modelo sistémico de gobierno electrónico con rostro social, debemos ver este tema vinculado también a la reforma y la modernización del Estado.

${ }^{60}$ Díaz-Canel, M. (2018) Clausura de la Primera Conferencia Nacional de la Unión de Informáticos de Cuba. Palacio de las Convenciones. La Habana. Disponible en: http://www.cubadebate.cu/noticias/2018/10/03/miguel-diaz-canel-clausura-conferencia-de-union-de-informaticos-de-cuba/\#.XEcs4jS73IU

${ }^{61}$ Confróntese, Amoroso Fernández, Y. et al. (2016) Big Data: una herramienta para la Administración Pública, Revista Ciencias de la Información, No. 8, Cuba; Ojeda Bello, Z. \& Amoroso Fernández, Y. (2016) La protección de los datos personales en Cuba desde la legislación vigente, Revista Justicia Juris, $\mathrm{N}^{\circ}$. 12, Colombia, pp.86-94

${ }^{62}$ Cfr. Amoroso Fernández, Y. (2014) Gobierno Electrónico: propuesta metodológica de desarrollo y evaluación, México; López Hernández, E. et al. (2016) iLex 1.0: Constitución de la República de Cuba desde su dispositivo móvil, Congreso Internacional de Información, La Habana. 
La estrategia de modernización tiene que tener tres características: ser gradual, generar redes de colaboración, crear las condiciones de interoperabilidad y transformar la cultura organizacional con el apoyo transformador del gobierno electrónico. El gobierno cubano ha tomado como sustento para la definición de la visión del "Gobierno Electrónico", los cuatro pilares fundamentales del proceso revolucionario cubano: la educación, la salud, la seguridad social y la cultura. Los cuales se trabajan a través del "Programa Rector para la Informatización de la Sociedad Cubana", estrategia que tiene al ciudadano en el centro de sus objetivos, buscando elevar su calidad de vida a través del uso de las Tic. Empero, los usuarios necesitan saber que sus comunicaciones con el Gobierno son seguras, y que sus documentos y transacciones electrónicas están reconocidos y protegidos por la ley. También es importante que todo proyecto se desarrolle basada en una filosofía de Open Data a modo de favorecer la interoperabilidad y la reutilización adecuada de los datos. ${ }^{63}$

La Agenda Digital de América Latina y el Caribe como resultado de la $6^{\text {ta }}$ Conferencia Ministerial de la Sociedad de la Información en América Latina y el Caribe (eLAC,2020) de 2018, Cartagena de Indias, Cuba participa, se declara el objetivo 10: "impulsar el gobierno electrónico centrado en el ciudadano, masificando la disponibilidad de trámites y servicios y la información pública, por múltiples canales y en todos los niveles de gobierno". ${ }^{64}$

Cuba presenta las condiciones para adoptar e implementar un efectivo gobierno digital con servicios sostenibles y centrado en la innovación, para lo cual hay que seguir procesos y actividades que se integren en un programa holístico estratégico que permita conducir paso a paso estas iniciativas, en un entorno de gobernanza regida por las disposiciones jurídicas. ${ }^{65} \mathrm{El}$ cuerpo jurídico que reconoce el Sistema de Información del Gobierno en Cuba es el Decreto Nº. 281

63 Véase, Cfr. Amoroso Fernández, Y. (2014) Gobierno Electrónico: propuesta metodológica de desarrollo y evaluación, México; Delgado, T. \& Sánchez Díaz, A. (2018) Repensando el gobierno electrónico: ventanilla única, servicios sostenibles y gobierno digital centrado en la innovación, Revista cubana de Administración Publica y Empresarial, $\mathrm{N}^{\circ}$. 3, La Habana.

${ }^{64}$ Véase, Welp, Y. (2008) América Latina en la era del gobierno electrónico. Análisis de la introducción de nuevas tecnologías para la mejora de la democracia y el gobierno, Revista Reforma y Democracia. N. 41, España; Unesco (2013) Enfoques Estratégicos sobre las TICS en América Latina y el Caribe. Oficina Regional de Educación para América Latina y el Caribe, Santiago de Chile

${ }^{65}$ Cfr. Delgado, T. \& Sánchez Díaz, A. (2018) Repensando el gobierno electrónico: ventanilla única, servicios sostenibles y gobierno digital centrado en la innovación, La Habana; Formentín Zayas, Y. (2012) La firma electrónica, su recepción legal. Especial referencia a la ausencia legislativa en Cuba, Revista IUS, Nº. 31, México.

(C) UNED. Revista de Derecho UNED, núm. 25, 2019 
de 2011. En su implementación con otros instrumentos legales que se diseñen deberán desarrollar las políticas de interoperabilidad de datos, basadas en estándares de todos los ámbitos que posibilite satisfacer integralmente los trámites que realiza la población. Su ejecución a nivel de todos los productores-proveedores de la Administración Pública en el país, debe conllevar a la generación de nuevas políticas para la publicación, uso, acceso, licenciamiento, distribución y/o comercialización de datos y servicios de datos, incluyendo la privacidad ciudadana. ${ }^{66}$

El Consejo de Ministros en el 2017 establece la política integral para el perfeccionamiento de la informatización de la sociedad junto a un grupo de instrumentos legales derivados de la misma, los que a consideración de los autores del artículo constituyen el principal marco legal del gobierno electrónico en el país, identificado como uno de los proyectos priorizados en el Programa Nacional asociado a esta política. ${ }^{67}$ Se reconoce por la Administración Pública que uno de los retos por alcanzar con el gobierno digital será el de avanzar en el ordenamiento de los Registros Públicos del país (lineamiento 273), tarea encomendada al Ministerio de Justicia, acompañado de la normativa legal recogida en el Decreto Ley No 335 de 2015 para que se conforme esta plataforma dentro del E-goverment como una página digital interactiva. Para avanzar en el tema de VU se necesita la gobernanza de interoperabilidad de gobierno electrónico/digital, entendida esta como el conjunto de acuerdos (gobernados por políticas) entre los gobiernos y los actores que participan en los procesos de interoperabilidad y a la forma de alcanzarlos. Para progresar en la Ventanilla única es la necesaria gobernanza para una efectiva interoperabilidad organizacional, legal, informacional y semántica. Las plataformas digitales basadas en la nube constituyen un pilar clave para minimizar el costo de despliegue de soluciones de VU y para la sostenibilidad de los servicios en línea. ${ }^{68}$

${ }^{66}$ Consúltese, Martino, A. (2015) Sociocibérnetica, Informática Jurídica e Infoética. Buenas prácticas y Lecciones aprendidas. Editorial UNIJURIS, Cuba; $C f r$. Delgado T. Ramírez Z. \& Amoroso Y. (2018) Hacia un gobierno abierto: necesidad de una política nacional de datos. Cibersociedad-Soñando y Actuando. Editorial Futuro. La Habana, pp. 172-188; Ojeda Bello, Z. (2015) El derecho a la protección de datos personales desde un análisis histórico-doctrinal, Revista Tla-melaua, №. 38, México.

${ }^{67}$ Cfr. Díaz-Canel M. (2018) Clausura de la Primera Conferencia Nacional de la Unión de Informáticos de Cuba. Disponible en: http://www.cubadebate.cu/noticias/2018/10/03/miguel-diaz-canel-clausura-conferencia-de-union-de-informaticosde-cuba/\#.XEcs4jS73IU

${ }^{68}$ Cfr. Delgado, T. \& Sánchez Díaz, A. (2018) Repensando el gobierno electrónico: ventanilla única, servicios sostenibles y gobierno digital centrado en la innovación, La Habana. 


\subsection{Génesis de la Ventanilla Única en la Administración Pública en Cuba}

La VU ha decursado similar al contexto foráneo, con las actividades vinculadas a la inversión extranjera dentro del Comercio Exterior, al amparo de lo regulado en la Ley No. 118 de 2014, Ley de Inversión Extranjera. Aquí existe un nexo con el Derecho Constitucional, el Derecho Administrativo, el Derecho Mercantil, el Derecho Ambiental, entre otras ramas. Los procesos que aquí se realizan vinculados a la EIA, la licencia ambiental, la certificación ambiental y otros actos administrativos dentro del entorno del comercio. Procesos que se ejecutan en el fomento de la inversión extranjera realizados en la Zona Especial de Desarrollo del Mariel, y en áreas de interés público ejecutado por el Ministerio de Ciencia, Tecnología y Medio Ambiente (CITMA) con la consulta de otros organismos, a tenor de los establecido en la Ley No .81 de 1997 y otros actos administrativos. Para la auditoría ambiental, le corresponde a la Contraloría General de la República a tenor de la Ley No 107 de 2009 y su Reglamento del 2010. ${ }^{69}$

Dentro del Derecho Ambiental patrio, sobre el tema se puede apreciar estudios realizados por Pereira Basanta sobre la autorización ambiental integrada, quien refiere que el Derecho Ambiental también está imbuido de los condicionamientos, exigencias y retos que impone la actual Sociedad de la Información y la Tecnología. En los tópicos ambientales, la alta complejidad de las interrelaciones que existen entre los distintos elementos que conforman el medio ambiente, los riesgos que trae aparejado el uso de tecnología en las actividades humanas, y la relación que se establece entonces entre el Derecho y la técnica, hacen que uno de los retos a los que se enfrenta el Derecho Ambiental sea el de aunar el conocimiento necesario, así como las técnicas para canalizar adecuadamente ese conocimiento, con vistas a enfrentarse mejor a la complejidad del bien

${ }^{69}$ Confróntese, Antúnez Sánchez, A. Tesis de maestría: La auditoría ambiental en Cuba, Universidad de Oriente (2005); Antúnez Sánchez, A. (2015) La auditoría ambiental: Una revisión y propuestas en clave de su función pública y dimensión empresarial, Revista Iberoamericana de Contabilidad de Gestión, № 26, España; Antúnez Sánchez, A. (2016) La potestad inspectiva v/s la auditoría pública. Ojeada histórica dentro del Derecho Administrativo Ambiental cubano. Revista Iberoamericana de Derecho Ambiental y los recursos naturales. Doctrina, legislación y jurisprudencia ambiental. No 8. Argentina; Antúnez Sánchez, A. y Ramírez Sánchez, A. (2018) El régimen jurídico de la inspección administrativa y los derechos sociales en Cuba. Apuntes para una reforma. Revista Derecho \& Paz, No. 38, Brasil.

(C) UNED. Revista de Derecho UNED, núm. 25, 2019 
jurídico que pretende tutelar. ${ }^{70}$ Para cerrar, se considera que, como antecedente en relación a los trámites realizados por los ciudadanos, se han llevado a cabo experimentos promovidos por la Administración Pública con el fin de agilizar los trámites en la relación con los administrados con la Unidad de Trámites y Servicios a la población en las provincias de Mayabeque y Artemisa. Se valora que ello constituye una primigenia aproximación a un sistema de VU que recurre a un modelo de agrupación física de servicios y una captación unificada del trámite como se significa en la teoría consulta up supra en el fomento de la digitalización de los servicios públicos en la transformación del modelo económico. ${ }^{71}$

\subsection{Asidero jurídico de la Ventanilla Única dentro del gobierno digital}

En Cuba, el 2019 trae un texto constitucional nuevo, introduce nuevos derechos o los llamados derechos de $3^{\mathrm{a}}$ generación, el que nos vincula al desarrollo del artículo es -el derecho al acceso a la información pública y a recibir información veraz, objetiva y oportuna-, en relación a lo que como Estado parte se firmó dentro del Sistema de Naciones Unidas descrito en el epígrafe up supra. ${ }^{72}$ La Administración Pública desde el año 2018 pondera el gobierno electrónico y el portal del ciudadano por los organismos de la Administración del Estado y órganos de gobierno. ${ }^{73}$

Se valora que la VUCA constituye un novedoso mecanismo en la gestión ambiental. Su fin es simplificar la materialización de la demanda de los diferentes actores involucrados en la emisión de permisos ambientales con el propósito de buscar una mayor racionalización de trámites y simplificación de procedimientos que permita asegurar el objetivo de protección ambiental, sin que ello signifique

${ }^{70}$ Pereira Basanta, J. Tesis de maestría: La autorización ambiental en el marco del procedimiento de evaluación de impacto ambiental: introducción a su régimen jurídico en Cuba, Universidad de La Habana (2011)

${ }^{71}$ Fraga Portes, Y. (2011) Cuba y la Informatización de los Servicios Jurídicos, Revista Monografías, España; Real Castro, J. (2018) Portal del ciudadano: una herramienta de gobierno electrónico en Pinar del Río, Taller Internacional las Tic en la Gestión de las Organizaciones, Informática 2018, La Habana; Bergara, M. et al. (2016) Transformaciones económicas en Cuba: una perspectiva institucional, Editorial Universidad de La Habana, Cuba.

${ }^{72}$ Constitución de la República de Cuba, 2019 (S/P G.O.)

${ }^{73}$ Cfr. Delgado T. Ramírez Z. \& Amoroso Y. (2018) Hacia un gobierno abierto: necesidad de una política nacional de datos. Cibersociedad-Soñando y Actuando. Editorial Futuro. La Habana, pp.172-188. 
demoras innecesarias o duplicidad de intervenciones de entidades estatales en el proceso requerido para obtener la aprobación de los estudios ambientales $\mathrm{u}$ otros permisos ambientales para el desarrollo de actividades económicas. Como herramienta de las Tic, es un mecanismo de gobierno electrónico, su implementación busca la transformación positiva de la relación entre el Estado y los titulares de proyectos de inversión, la relación entre entidades de gobierno, así como la relación entre el Estado y toda la sociedad civil que se involucra en los procesos de autorización ambiental desarrollados dentro de la gestión ambiental rectorada por el CITMA en la modernización del Estado con el gobierno electrónico. ${ }^{74}$

\subsection{La Ventanilla Única de Certificación Digital en el Derecho Ambiental en Cuba}

Al analizar la Ley №. 81 de 1997, se corrobora que no establece entre el desarrollo de sus artículos un reconocimiento a la VUCA, relacionada con las herramientas de gestión. No obstante, la Resolución No. 224 de 2014 del CITMA, a tenor del Decreto No$^{\circ} .327$ de 2014, Reglamento del Proceso Inversionista, establece el procedimiento para la evaluación de los estudios de factibilidad de las inversiones vinculadas a las esferas de la ciencia, la tecnología y el medio ambiente. Este cuerpo administrativo en su artículo 2, regula: "Ventanilla Central": el procedimiento utilizado para facilitar el proceso de tramitación de la documentación correspondiente y que por lo general establece un solo momento de gestión entre dos partes, donde una de ellas actúa como gestora general de acciones relacionadas con terceros. Para la entrega de la Licencia Tecnológica de conjunto con el criterio técnico de otros organismos de la Administración Pública como el Ministerio de Salud Pública, el Instituto de Planificación Física, el Ministerio de las Fuerzas Armadas dentro del Sistema de Ventanilla Central del CITMA. ${ }^{75}$

${ }^{74}$ Consúltese, Rey Santos, O. (2007) Sobre los Instrumentos de la gestión ambiental, Derecho Ambiental Cubano, $2^{\text {da }}$ edición, Editorial Félix Varela, La Habana; Cánovas González, D. (2010) Licencia ambiental y sistemas de responsabilidad. El Derecho Público en Cuba a comienzos del siglo XXI, Universidad de La Habana, Cuba. Antúnez Sánchez, A. (2016) La gestión ambiental. Incidencia en el comercio, Revista Veredas do Direito Ambiental e desenvolvimiento sustentavel, Brasil; Rey Santos O. y Cruz Sardiñas, T (2017) La Ley del Medio Ambiente: 20 años después, Editorial UNIJURIS, La Habana.

${ }^{75}$ Decreto No. 327, Reglamento del Proceso Inversionista, G. O. E. No. 5 de 23 enero 2015. 
La implementación de la VUCA en la nación establecerá un proceso de descentralización, con ello las autoridades ambientales han transferido sus funciones ambientales y de ordenamiento territorial a los gobiernos regionales para su concreción. Ello favorecerá la articulación intersectorial con otros organismos de la Administración Pública para defender la fiscalización ambiental. Para ello tiene que existir una coordinación vertical y horizontal por los servidores públicos que ejercitan el control ambiental. En correspondencia con el Derecho Ambiental Internacional en la Agenda 2030 para el Desarrollo Sostenible y el Acuerdo de París sobre el cambio climático de 2014, instrumentos que presionan a la comunidad internacional a trabajar en favor del desarrollo sostenible y el bienestar común. ${ }^{76} \mathrm{El}$ CITMA lo contextualiza en el Plan de Estado para el cambio climático "Tarea Vida”, en armonía con lo establecido en la Constitución de la República de Cuba de 2019. ${ }^{77}$

Estos elementos abordados apuntan a que habrá que ponderar nuevos enfoques en el estudio del Derecho Administrativo por la academia con las herramientas de las Tic, las que vienen transformando las maneras de actuación de la Administración Pública en el siglo XXI, creando una relación telemática entre Administración Pública y ciudadanos. ${ }^{78}$ De aquí que pondere la necesidad de la formación jurídica con la integración de los contenidos que aportan las Tic en esta sociedad digital.

\section{CONCLUSIONES}

Las Tic han abierto un campo de posibilidades casi ilimitadas para comunicar y compartir la información. La versatilidad de la información digitalizada para su procesamiento (codificación, almacenaje, selección y recuperación) y la posibilidad de su distribución a través de Internet, facilitan enormemente los usos de la información

76 CEPAL (2016) Agenda 2030 y los Objetivos de Desarrollo Sostenible. Una oportunidad para América Latina y el Caribe, Editorial ONU, Santiago de Chile; Acuerdo de Paris (2015) ONU, Nueva York.

77 Plan de Estado para el enfrentamiento del cambio climático. (2018) Tarea Vida, Ministerio de Ciencias, Tecnología y Medio Ambiente, La Habana.

${ }^{78}$ Véase, Gómez Puente, M. (2007) La Administración electrónica. La autorización administrativa. La enseñanza del Derecho administrativo hoy, Editorial Aranzadi, Navarra; Martínez Gutiérrez, R. (2009) Administración Pública electrónica, Editorial Civitas, Navarra; Bello Paredes, S. (2011) Las Tic y el Derecho Administrativo como objeto y método de aprendizaje: una experiencia de innovación docente en la Universidad de Burgos, II Jornadas sobre docencia del Derecho Y TIC. Universidad de Burgos, España. 
y el conocimiento y, por tanto, las posibilidades de socialización y apropiación cognitiva del acervo informacional y cultural.

La VUCA es un mecanismo en la gestión ambiental. Su finalidad es simplificar la materialización de la demanda de los diferentes actores involucrados en la emisión de permisos ambientales con el propósito de buscar una mayor racionalización de los trámites y la simplificación de procedimientos que permitan asegurar el objetivo de protección ambiental sin que ello signifique demoras innecesarias o duplicidad de intervenciones de entidades estatales en el proceso requerido para obtener la aprobación de los estudios ambientales u otros permisos ambientales requeridos para el desarrollo de actividades económicas. Como mecanismo de gobierno electrónico busca la transformación positiva de la relación telemática entre el Estado y los titulares de los proyectos de inversión, la relación entre entidades de gobierno, así como la relación entre el Estado y toda la sociedad civil en la gestión ambiental dentro de la modernización del Estado con el gobierno electrónico/digital.

El Gobierno Digital constituye una herramienta eficaz para la Administración Pública con el fin de propiciar la participación ciudadana y promover de esta manera la colaboración de la comunidad en función del progreso de un país en beneficio de todos. La participación ciudadana reconocida desde los textos constitucionales establece como un derecho de los ciudadanos para mantener las actividades de control, colaboración e información sobre el Estado actual de su país con transparencia.

\section{REFERENCIAS BIBLIOGRÁFICAS}

AA. VV. (2003) Firma digital y Administración Pública, INAP, Madrid.

AA. VV. (2004) Administración electrónica y procedimiento administrativo, Ministerio de Economía, Madrid, 2004.

Álamo González, N. (2007) La utilización de las nuevas tecnologías entre las Administraciones públicas y los ciudadanos, REDA, $\mathrm{N}^{\circ} 133$, España.

Aldana, M. (2016) Caminando hacia la ventanilla única de certificación ambiental, Revista Circulo de Derecho Administrativo, Perú.

ArenA, G. (2004) E-Government y Nuevos Modelos de Administración. Revista de Administración Pública No 163 , España. 
Amoroso Fernández, Y. et al. (2016) Big Data: una herramienta para la Administración Pública, Revista Ciencias de la Información, №. 8, Cuba.

Amoroso Fernández, Y. (2014) Gobierno Electrónico: propuesta metodológica de desarrollo y evaluación, UNAM, México.

Amoroso Fernández, Y. (2000) Gobierno electrónico. El reto de la gestión y conservación permanente de la información digital, Revista UNAM, México.

AMOROSO FERNÁNDEZ, Y. (2017) Un acercamiento a la socio-cibernética y la infoética en las Tic: valores éticos y derecho, Revista Argumentos de Razón Técnica, No 20, España, pp.119-148

Amoroso Fernández, Y. (2008) Aspectos éticos y legales de la información digital, Facultad de Derecho, Universidad de Valencia, España.

AMOROSO Y. ET AL. (2018) GOBIERNO ELECTRÓNICO: REFLEXIONES DESDE LA UIC. Cibersociedad - SOÑando y actuando. Editorial Futuro, La Habana, pp.155-171.

Antúnez SÁnchez, A. Tesis de Maestría: La auditoría ambiental en Cuba, Universidad de Oriente (2005)

Antúnez Sánchez, A. \& López Espinosa, E. (2018) La educación ambiental. Su reconocimiento desde el Derecho internacional, Revista de Derecho Ambiental, Doctrina, Jurisprudencia, Legislación y Práctica, $N^{\circ}$ 56, Argentina.

ANTÚNEz SÁNCHEZ, A. (2018) La formación jurídico ambiental mediada por el uso de las Tic, Revista Iberoamericana de bioeconomía y cambio climático, $\mathrm{N}^{\circ} 8$, Nicaragua.

ANTúnez SÁNchez, A. y Sánchez Ramírez, A. (2018) La inspección ambiental. La evaluación de impacto ambiental. La autorización ambiental y la auditoría ambiental, Revista Excelencia Administrativa, $\mathrm{N}^{\circ} 38$, México.

ANTúnez SÁNchez, A. (2016) La gestión ambiental. Incidencia en el comercio, Revista Veredas Do Direito Ambiental e Desenvolvimiento Sustentavel, No 26, Brasil.

Barriuso RuIz, C. (2007) Administración electrónica, Editorial Dykinson, Madrid.

BARriuso Ruiz, C. (2002) La contratación electrónica. Editorial Dykinson, Madrid. 
Blasco Díaz, J. (2008) Los derechos de los ciudadanos en su relación electrónica con la Administración. Derechos fundamentales y otros estudios, Editorial Justicia de Aragón, Zaragoza.

Bernadí GIL, X. (2005) Derecho público y Administración electrónica: una visión panorámica, Nuevas políticas públicas. Anuario multidisciplinar para la modernización de las Administraciones públicas, $\mathrm{N}^{\circ} 1$, España.

Bergara, M. et al. (2016) Transformaciones económicas en Cuba: una perspectiva institucional, Editorial Universidad de La Habana, Cuba.

Cabanellas G. \& Palazzi P. (2004) DeRecho de InTERnet, Editorial Heliasta S.R.L., Argentina.

CAMACHO, G. (2000) Los principios de eficacia y eficiencia administrativas, Editorial Conosur, Argentina.

CANALS AMETLler, D. (2012) Simplificación administrativa y directiva de servicios: objetivos, medios e incidencias, el procedimiento administrativo: descarga burocrática, INAP, España.

CASTELls, M. (2005) La era de la información. La sociedad red, Editorial Alianza, Madrid.

CASTILlO Y. (2016) VENTANILLA ÚNICA DE TRÁMITES - UNA APROXIMACIÓN CONCEPTUAL. MONOGRAFÍAS-ADMINISTRACIÓN Y FINANZAS. DiSPONIBLE EN: HTTPS://WWW.MONOGRAFIAS.COM/DOCS113/VENTANILLA-UNICA-TRAMITES-APROXIMACION-CONCEPTUAL/VENTANILLA-UNICA-TRAMITES-APROXIMACION-CONCEPTUAL2.SHTML.

CASTOLDI, P. (2002) El gobierno electrónico como un nuevo paradigma de Administración. Revista Prudentia Juris, $\mathrm{N}^{\circ}$ 55. Buenos Aires.

CÁNOVAS GonZÁLEZ, D. (2010) Licencia ambiental y sistemas de responsabilidad. El Derecho Público en Cuba a comienzos del siglo XXI, Universidad de La Habana, Cuba

CLAD (2007) Carta Iberoamericana de Gobierno Electrónico. Chile.

Cotino Hueso, L. (2006) El Voto Electrónico o la Casa por el Tejado. La Necesidad de Construir la Democracia y Participación Electrónicas por los Cimientos. Libertades, Democracia y Gobierno Electrónicos. Editorial Comares, Granada.

Celaya, J. (2008) La empresa en la web 2.0, Editorial Gestión 2000, Barcelona. 
Cerrillo Martínez, A. (2007) La Administración Electrónica. Editorial Cizur Menor, Aranzadi.

Cerrillo Martínez, A. (2012) La contribución de las Tic a la mejora de la transparencia administrativa. Revista Arbor Ciencia, Pensamiento y Cultura, Vol. 188, España.

CEPAL (2007) LIBRO BLANCO DE INTEROPERABILIDAD DE GOBIERNO ELECtRóNico PARA AMÉRICA LATINA Y EL CARIBE. CHILE.

CEPAL (2018) $6^{\text {TA }}$ CONFERENCIA MINISTERIAL SOBRE LA SOCIEDAD DE LA INFORMACIÓN DE AMÉRICA LATINA Y EL CARIBE (ELAC2020).

CEFACT/ONU (2005) RECOMENDACIONES Y DIRECTRICES PARA EL ESTABLECIMIENTO DE UNA VENTANILLA ÚNICA. UNITEd Nations PUblications. GINEBRA.

CEPAL/ONU (2007) LIBRO BLANCO DE INTEROPERABILIDAD DE GOBIERNO ELECTRÓNICO PARA AMÉRICA LATINA Y EL CARIBE. VERSIÓN 3.0. UNITED Nations Publications. Ginebra.

Cierco SEIRA, C. (2009) Algunas reflexiones sobre la simplificación de los procedimientos administrativos a la luz de los avances de la Administración electrónica, Revista General de Derecho Administrativo, $N^{\circ}$. 19, España.

Cruz Rivero, D. (2005) Análisis de los Antecedentes del Concepto de Firma Electrónica como Equivalente a la Firma Manuscrita. Revista de Contratación Electrónica $\mathrm{N}^{\mathrm{o}} 60$, España.

Cruz Rivero, D. (2006) El DNI Electrónico y el Mercado de las Entidades de Certificación. Revista de Contratación Electrónica. $\mathrm{N}^{\mathrm{o}}$ 69, España.

CRIADO, J. (2009) Gobierno electrónico en Latinoamérica: Aproximación desde una perspectiva intergubernamental, Estado, Gobierno, Gestión Pública. Revista Chilena de Administración Pública, $\mathrm{N}^{\circ}$. 14, Chile.

DelPiazzo C. (2001) ADECUACIÓN DEL DERECHO A LA NECESIDAD DE LA FIRMA ELECTRÓNICA, Informática y Derecho: Aportes de doctrina internacional, Editorial Depalma, Buenos Aires.

DelPiazzo, C. (2003) El principio de seguridad jurídica en el mundo virtual, Anuario Derecho Informático, FCU Montevideo.

Delpiazzo, C. (2005) Derecho y nuevas tecnologías de la información en los umbrales del siglo XXI, Anuario Derecho Informático, F.C.U. Montevideo. 
Delgado, T. \& Sánchez Díaz, A. (2018) Repensando el gobierno electrónico: ventanilla única, servicios sostenibles y gobierno digital centrado en la innovación, Revista cubana de Administración Publica y Empresarial, №. 3, La Habana.

Delgado T. Ramírez Z. \& Amoroso Y. (2018) Hacia un gobierno ABIERTO: NECESIDAD DE UNA POLÍTICA NACIONAL DE DATOS. CIBERSOCIEDaD - Soñando y ACtuando. Editorial Futuro. La Habana, pp. 172188.

DiÉGUEZ, G. et al. (2015) Escenarios y perspectivas del gobierno electrónico en América Latina y el Caribe, CIPECC, Buenos Aires.

Díaz-Canel, M. (2018) Clausura de la Primera Conferencia Nacional de la Unión de Informáticos de Cuba. Palacio de las Convenciones. La Habana. Disponible en: http://www.cubadebate.cu/noticias/2018/10/03/miguel-diaz-canel-clausura-conferencia-de-unionde-informaticos-de-cuba/\#.XEcs4jS73IU

Delgado Novoa, M. (2013) Necesidad de una ley de protección de datos personales en Cuba, Observatorio Iberoamericano de Protección de Datos, España.

Holmes, D. (2001) E-Gov, e-Business Strategies for Government. Nicholas Brealy Publisihing, Londres.

Hood, C. (2010) Accountability and Transparency: Siamese Twins, Matching Parts, Awkward Couple? West European Politics, №. 5, pp.989-1009.

Embid Irujo, A. (2012) La Evaluación de impacto ambiental en la Unión Europea. Revista de Justicia Administrativa. № 57. España.

Fernández AlLer, C. (2012) Algunos retos de la protección de Datos en la sociedad del conocimiento. Especial detenimiento en la computación en nube (cloud computing), Revista de Derecho UNED, No. 10, España.

Font Llovet, T. (1994) Instrumentos jurídicos en la protección del medio ambiente, Revista Aragonesa de Administración Pública, No .5 , España, p. 50.

Formentín ZaYAS, Y. (2012) La firma electrónica, su recepción legal. Especial referencia a la ausencia legislativa en Cuba, Revista IUS, No. 31, México.

Frosini, V. (1978) Cibernética, Derecho y Sociedad. Editorial Tecnos, Madrid. 
García Rubio, F. (2003) Las nuevas tecnologías ante el Derecho y la organización administrativa. Un estudio sobre las repercusiones en la Administración Local. INAP. España.

GAMERo CASADO, E. (2008) El procedimiento administrativo electrónico en las entidades locales, con especial referencia al uso de la firma electrónica, Informe sobre la administración electrónica local, Fundació Carles Pi i Sunyer, Barcelona.

GAMERo CASAdo, E. (2009) Ventanilla única y administración electrónica en la transposición de la directiva de servicios, Universidad Pablo de Olavide de Sevilla.

Galván RuIz, J. \& García López, P. (2007) La Administración Electrónica en España. Editorial Ariel, España.

GaLindo, F. (2006) Gobierno, Derecho y Tecnología: Las actividades de los Poderes Públicos. Editorial Thomson Civitas, España.

Gómez Paidós, V. (2006) Sobre las aportaciones y límites de la Red y las redes sociales, para vertebrar nuevas formas de participación cívica en el espacio público, Barcelona.

GonZález de la Garza, L. (2008) Voto Electrónico por Internet, Constitución y Riesgos para la Democracia. Editorial Edisofer. España.

GonZÁLEZ, P. (2014) Informe 2014 de Naciones Unidas sobre Gobierno Electrónico. Disponible en: http://www.agesic.gub.uy/innovaportal/ file/1443/1/agesic_agendadigitl_2011_2015.pdf.

González, C. (2013) Realidad Aumentada. Bubok Publising. United State.

Guardián Horta, C. (2010) ¿Transparencia? Open Government: Gobierno abierto, Editorial Algón, España.

Manchado, A. (2010) Gobierno abierto: una aproximación desde el Estado. Open Government: Gobierno abierto, Editorial Algón, España.

Martínez Gutiérrez, R. (2009) Administración Pública electrónica, Editorial Civitas, Cizur Menor.

Martínez GutiérRez, R. (2010) Identificación y Autenticación: DNI Electrónico. Administración Electrónica y Ciudadanos. Editorial Civitas Thomson. España.

Martínez-Villalva, J. (2014) La cuarta ola de derechos humanos: los derechos digitales, Revista Latinoamericana de Derechos Humanos, México. 
Martino, A. (2015) Sociocibérnetica, Informática Jurídica e Infoética. Buenas prácticas y Lecciones aprendidas. Editorial UNIJURIS, Cuba.

Meneses Rocha, M. (2015) Ciberutopías. Democracia, redes sociales y movimientos-red. Editorial Porrúa, México.

Montesinos, V. (2009) Transparencia y responsabilidad en el sector público: el papel de la información en tiempos de crisis. Revista AECA $\mathrm{N}^{\circ} .87$, España, pp.26-28.

Martín Mateo, R. (1997) Derecho Administrativo Ambiental, $6^{\text {ta }}$ edición, Editorial Trivium, España.

Martín Delgado, I. (2009) Naturaleza, concepto y régimen jurídico de la actuación administrativa automatizada, RAP, No. 180, España.

Morcillo Moreno, J. (2005) La Identidad Digital, mediante el documento nacional de identidad electrónico. Administraciones Públicas y Nuevas Tecnologías. Editorial Lex Nova. España.

Mira Ros, C. (2010) El expediente judicial electrónico, Editorial Dykinson, Madrid.

Naciones Unidas (2012) Estudio sobre GobIerno Electrónico. DePaRTAMENTO DE ECONOMía y Asuntos Sociales. New YorK.

Organización Mundial de Aduanas (2012) CÓMO CONSTRUIR UN ENTORNO DE VENTANILLA ÚNICA. VOL. 1. GUÍA EJECUTIVA. OMC.

Oliver Cuello, R. (2009) La regulación de la administración electrónica tributaria, Administración Electrónica Tributaria, Editorial Bosch, Barcelona.

OchOA Monzón, J. (200) ¿Hacia la ciberadministración y el ciberprocedimiento? El Derecho Administrativo en el umbral del siglo XXI. Editorial Tirant lo Blanch-Generalitat Valenciana, España.

Olivera, N. (2010) Estado de la cuestión de la relación entre Derecho e Informática, Anales, Revista de la Facultad de Ciencias Jurídicas y Sociales de la Universidad Nacional de la Plata, No 40, Argentina.

Ortiz Chaparro, F. (1995) El Teletrabajo. Una Nueva Sociedad Laboral en la Era de la Tecnología. Editorial McGraw \& Hill. España.

OJEDA Bello, Z. et al. (2017) Cuba ante el desafío de asegurar la información personal, Revista Dike, №. 21, Universidad de Puebla, México.

Tascón, M. (2013) Big Data: Pasado, presente y futuro. Editorial Telos. España. 
Palomar Olmeda, A. (2007) La actividad administrativa efectuada por medios electrónicos, Navarra.

Palomar Olmeda, A. (2008) Gestión electrónica de los procedimientos. La Ley de Administración Electrónica. Comentario sistemático a la Ley 11/2007 de Acceso Electrónico de los Ciudadanos a los Servicios Públicos, Editorial Aranzadi, Cizur Menor.

Parejo Alfonso, L. \& Alfonso D. (2012) Autorizaciones y Licencias, Hoy, Editorial Tirant lo Blanch, España.

Paetau, M. (2006) Niklas Luhmann y la Cibernética. Socio-cibernética. Lineamientos de un paradigma, España, pp. 161-192.

Piana, R. (2010) La Carta Iberoamericana de Gobierno Electrónico. Orientaciones y buenas prácticas. Democracia Electrónica. Universidad de Zaragoza. España.

PÉrez Luño, A. (2000) La seguridad jurídica. Boletín de la Facultad de Derecho $\mathrm{N}^{\text {o. }} 15$, UNED, España.

Pérez Luño, A. (2004) ¿Ciberciudadani@o Ciudadani@.Com?, Editorial Gedisa, Barcelona.

Pérez LuÑo, A. (2006) La tercera generación de derechos humanos, Editorial Thomson Aranzadi, Pamplona.

Pérez Luño, A. (2014) Los Derechos Humanos ante las Nuevas Tecnologías. El Tiempo de los Derechos, Editorial Tirant lo Blanch, Valencia.

Pérez Luño, A. (2014) Teledemocracia, ciberciudadania y derechos humanos, Revista Brasilera de Políticas Públicas, No.2, Brasil.

Pérez LuÑo, A. (2011) Nuevas tecnologías, informática y derechos, Revista Lex, España.

Prenski, M. (2010) Nativos e Inmigrantes Digitales, Editorial SEK, España.

Piñar MaÑas, J. (2007) Revolución tecnológica, Derecho administrativo y Administración pública, La autorización administrativa. La Administración electrónica. La enseñanza del Derecho administrativo hoy, Navarra.

Pintos, C. (2012) Open Data, reutilización de la información pública para crear una nueva empresa, Editorial Netbiblo, España.

Punzón Moraleda, J. et al. (2009) La utilización de medios electrónicos, informáticos y telemáticos en la Ley 30/2007, de contratos del Sector Público, La Ley, Editorial Las Rozas, España. 
PLAN DE ESTADO PARA EL ENFRENTAMIENTO DEL CAMBIO CLIMÁTICO (2018) TAREA VIDA, Ministerio de Ciencias, Tecnología y Medio Ambiente, La Habana.

Rivero Ortega, R. (2010) Principio de celeridad, Los principios jurídicos del Derecho Administrativo, Editorial La Ley, Madrid.

Rivero Ortega, R. (2007) El Expediente Administrativo. De los Legajos a los Soportes Electrónicos. Editorial Thomson-Aranzadi. Navarra.

RIVERo ORTEGa, R. (2010) Simplificación administrativa y administración electrónica: objetivos pendientes en la transposición de la directiva de servicios, Universidad de Salamanca, España.

Ríos, D. (2008) Democracia Electrónica, Editorial LID, Madrid.

Robles Morales, J. (2009) Ciudadanía digital: una introducción a un nuevo concepto de ciudadano. Editorial UOC, Barcelona.

Rojas Amandi, V. (2000) El Uso de Internet en el Derecho. Oxford University Press, México.

Rey Santos O. y Cruz Sardiñas, T (2017) La Ley del Medio Ambiente: 20 años después, Editorial UNIJURIS, La Habana.

Rey SANTOS, O. (2007) Sobre los Instrumentos de la gestión ambiental, Derecho Ambiental Cubano, $2^{\mathrm{da}}$ edición, Editorial Félix Varela, La Habana

Real Castro, J. (2018) Portal del ciudadano: una herramienta de gobierno electrónico en Pinar del Río, Taller Internacional las Tic en la Gestión de las Organizaciones, Informática 2018, La Habana;

Unesco (2013) ENFOQUES ESTRATÉGICOS SOBRE LAS TICS EN AMÉRICA LAtina Y EL CARIBE. Oficina Regional de EduCación para AMÉRICA LATINA Y EL CARIBE, Santiago de Chile.

Ugalde, V. (2004) Sobre la digitalización de trámites en la transición al e-gobierno, Revista Gestión y Política Pública, № 1, España, pp. 41-80.

Ros, M. (2009) Evolución de los servicios de redes sociales en Internet. Revista el Profesional de la Información, №. 18, España. Disponible en: http://www.elprofesionaldelainformacion.com/contenidos/2009/septiembre/09.pdf

Rossel, P. et al. (2006) Mobile' E-government Options: Between Technology-driven and User-centric. The Electronic Journal of E-government, $\mathrm{N}^{\circ}$. 2, USA, pp. 79-86. 
SÁEz VACAs, F. (2006) Más allá de la Internet, Revista Isegoría, № 34, España.

Sancho Royo, D. (2005) Sociedad de la información y gobierno, Instituto Andaluz de Administración Pública, Sevilla.

SALINAS, J. (2003) Comunidades virtuales y aprendizaje digital. Revista Edutec, $\mathrm{N}^{\circ} .54$, España.

SÁnchez SÁNcheZ, Z. (2009) Administración electrónica y Directiva de Servicios: ¿al servicio del mercado o paradigma de buena administración?, Mercado europeo y reformas administrativas. La transposición de la Directiva de Servicios en España, Editorial Civitas, Navarra.

Santamaría Pastor, J. (2009) Principios de Derecho Administrativo, Editorial Iustel, España.

Salazar Solís, L. (2006) Ventanilla única de gobierno electrónico. Colección documentos de trabajo sobre e-Gobierno. Red de Líderes de Gobierno Electrónico de América Latina y El Caribe.

SORIANO GARcía, J. (2011) El Derecho Administrativo y los desafíos del siglo XXI, Editorial Aranzadi, España. pp. 1-29.

SuñE Llinas, E. (2000) Tratado de Derecho Informático. Introducción y Protección de datos personales, $1^{\mathrm{a}}$ edición, Editorial Universidad Complutense de Madrid, España.

SuñE Llinas, E. (2016) Derecho informático de las cosas o de segunda generación: El Derecho de la Informática en la $4^{a}$ Revolución Industrial o de la Productividad, Revista Ambiente Jurídico, №. 19, Colombia.

Suñé LlinÁs, E. (2016) ¿Tres o cuatro generaciones de Derechos Humanos? Aporte de claridad conceptual a una feliz ocurrencia. Los Derechos Humanos en el siglo XXI. Editorial Porrúa, México.

SuÑÉ LlinÁs, E. (2004) La Ventanilla Única Electrónica. Actas del Xo Congreso Iberoamericano de Derecho e Informática. Centro de Estudios en Derecho Informático, Chile.

Suñé LlinÁs, E. (2016) Prólogo de la publicación Bancos de Datos: pasado, presente y futuro. Universidad Complutense de Madrid, España.

LAGARES, D. (2000) Internet y el Derecho, Editorial Carena, Barcelona. 
Lathrop, D. \& Ruma, L. (2010) Open Government. Collaboration, Transparency, and Participation in Practice, Editorial O'Reilly Media. Sebastopol.

Lozano Cutanda, B. (2004) Derecho Ambiental Administrativo, $5^{\text {ta }}$ edición, Editorial Dykinson, España.

LóPez Menudo, F. (1992) Los principios generales del procedimiento administrativo, Revista de Administración Pública, $\mathrm{N}^{\circ} 129$, España.

López Hernández, E. et al. (2016) iLex 1.0: Constitución de la República de Cuba desde su dispositivo móvil, Congreso Internacional de Información, La Habana.

Luz Clara, B. (2001) Manual de Derecho Informático, Editorial Jurídica Nova Tesis, Argentina.

Junceda Moreno, J. (2016) Obligaciones sobre transparencia. Protección de datos. Sobre los límites de la transparencia en el ámbito local. La Administración Práctica, No . 8, España. pp. 55-61.

VALERo TorRiJos, J. (2007) Régimen Jurídico de la e-Administración. El uso de medios informáticos y telemáticos en el procedimiento administrativo, Editorial Comares, Granada.

Valero Torrijos, J. (2000) Administración Pública, ciudadanos y nuevas tecnologías. El Derecho Administrativo en el umbral del siglo XXI. Editorial Tirant lo Blanch, Valencia.

Valenzuela Rivera, M. (2007) Firma digital. Consideraciones jurídicas, Revista Jurídica, Universidad San Carlos, Guatemala.

VARgas, F. (2016) La nueva economía digital, Tribuna del Abogado, No. 197, Montevideo, p. 24 y ss.

Villarejo Galende, H. (2008) La simplificación administrativa en la Directiva relativa a los servicios en el mercado interior. Sus repercusiones en la administración electrónica española y el desafío que plantea su transposición, Revista de Derecho de la Unión Europea, $\mathrm{N}^{\circ} 14$, España.

VID Rico, M. (2003) Comercio Electrónico, Internet y Derecho, Editorial Legis, Caracas, pp. 58 y ss.

Welp, Y. (2008) América Latina en la era del gobierno electrónico. Análisis de la introducción de nuevas tecnologías para la mejora de la democracia y el gobierno, Revista Reforma y Democracia. No. 41. España. 